\title{
Estimating the Lithospheric Flexure of a Plate with Non-uniform Flexural Rigidity: A Quantitative Modelling Approach
}

\section{Mingju Xu (D11738013@zju.edu.cn)}

Zhejiang University School of Earth Sciences https://orcid.org/0000-0001-6437-1634

\section{Zhao-Cai Wu}

Second Institute of Oceanography State Oceanic Administration: Second Institute of Oceanography Ministry of Natural Resources

\section{Fei Ji}

National Institute of Natural Hazards: Institute of Crustal Dynamics

\section{Ai-Guo Ruan}

Second Institute of Oceanography State Oceanic Administration: Second Institute of Oceanography Ministry of Natural Resources

\section{Chun-Feng Li}

Zhejiang University

\section{Jin-Yao Gao}

Second Institute of Oceanography State Oceanic Administration: Second Institute of Oceanography Ministry of Natural Resources

\section{Full paper}

Keywords: Loading of the earth, Effective elastic thickness, Lithospheric flexure, Error analysis

Posted Date: May 5th, 2021

DOl: https://doi.org/10.21203/rs.3.rs-470814/v1

License: (c) (i) This work is licensed under a Creative Commons Attribution 4.0 International License. Read Full License 


\section{Estimating the lithospheric flexure of a plate with non-uniform \\ 2 flexural rigidity: A quantitative modelling approach}

3 Ming-Ju Xu ${ }^{1,2,3}$, Zhao-Cai $\mathrm{Wu}^{3}$, Fei Ji ${ }^{4}$, Ai-Guo Ruan ${ }^{1,3}$, Chun-Feng $\mathrm{Li}^{5,2,6}$, Jin-Yao Gao ${ }^{3}$

$5 \quad{ }^{1}$ School of Earth Sciences, Zhejiang University, Hangzhou 310007, China.

$6 \quad{ }^{2}$ Department of Marine Sciences, Zhejiang University, Zhoushan 316021, China.

$7 \quad{ }^{3}$ Key Laboratory of Submarine Geosciences, SOA \& Second Institute of Oceanography, MNR,

8 Hangzhou 310012, China.

$9 \quad{ }^{4}$ National Institute of Natural Hazards, MEMA, Beijing 100085, China.

$10 \quad{ }^{5}$ Hainan Institute, Zhejiang University, Sanya, 572025, China

$11{ }^{6}$ Laboratory for Marine Mineral Resources, Qingdao National Laboratory for Marine Science

12 and Technology, Qingdao 266237, China.

14 E-mail addresses: 11738013@zju.edu.cn (M. Xu),wuzc@sio.org.cn (Z. Wu), jifeii@163.com (F.

15 Ji), ruanag@163.com (A. Ruan), cfli@zju.edu.cn (C. Li), jygao@mail.hz.zj.cn (J. Gao)

Corresponding authors : Zhao-Cai Wu \& Fei Ji

17 The Second Institute of Oceanography, MNR, No.36 Baochubei Road, Hangzhou 310012,

18 China. E-mail: wuzc@ sio.org.cn

19 National Institute of Natural Hazards, MEMA, No.1 Anningzhuang Road, Beijing 100085,

20 China. Email: jifeii@ 163.com 


\section{Abstract}

Lithospheric deformation is a fundamental process in plate tectonics. It is therefore critical

24 to determine how the lithosphere responds to geological loads to better understand tectonic 25 processes. The lithosphere can be modelled as the flexure of a thin, elastic plate over long-term $26\left(>10^{5} \mathrm{yr}\right)$ geological timescales. The partial differential equation for the flexure of an orthotropic 27 plate is used indirectly to calculate theoretical admittance and coherence, which are then compared against the observed admittance and coherence to invert for the non-uniform flexural

29 rigidity (or effective elastic thickness, $T_{e}$ ) of the plate. However, the process for accurately 30 recovering variable lithospheric flexure remains unresolved, as the classical lithospheric model 31 may overestimate the deflection of the plate. Here we adopt the classic lithospheric model with applied external and internal loads at the surface and Moho, respectively, and assume that the

33 compensation material is denser than the mantle material beneath the Moho. The lithospheric

34 flexure errors are derived mainly from the $T_{e}$ and Moho recovery errors in this lithospheric 35 model. Synthetic modelling is then performed to analyse the influence of the $T_{e}$ and Moho errors. 36 The analysis of synthetic modelling shows that: 1) the inverted flexure values are insensitive to 37 the $T_{e}$ errors, and the $T_{e}$ error-induced flexure errors exhibit a rippling pattern; 2) the Moho 38 error-induced flexure errors occur mainly in the low $T_{e}$ regions, and the Moho disturbance is 39 alleviated by both an attenuation coefficient of the form $-\left(\rho_{F}-\rho_{m}\right) /\left(\rho_{m}-\rho_{c}\right)$ and the

40 lithospheric strength as the Moho disturbance propagates into the lithospheric flexure error; and 413 ) the lithospheric flexure errors are dominated by the $T_{e}$ and Moho errors in the high and low $T_{e}$ 42 regions, respectively.

45 Keywords: Loading of the earth; Effective elastic thickness; Lithospheric flexure; Error analysis 


\section{Introduction}

48 Our understanding of the mechanics of the Earth's crust and lithosphere have been greatly

49 advanced since the 1970s, via numerous modelling, including experimental examinations of the

50 behaviour of physical bodies (e.g., Dorman \& Lewis 1970, 1972; Lewis \& Dorman 1970a,

51 1970b) and derivations of the mathematics that describe lithospheric processes (e.g., McNutt

52 1980; Forsyth 1985; Burov \& Diament 1992; Banks et al. 2001; Braitenberg et al. 2002;

53 McKenzie 2003; Kirby \& Swain 2009; Zhang et al. 2018). These studies followed the principle

54 that the lithosphere can be idealised if the main structural features are considered, thereby

55 allowing simplified models to capture the key structures and geodynamics of the lithosphere.

56 However, no information on the internal structure of the lithosphere has been used in these

57 investigations, and its mechanical properties, such as the flexure of the tectonic plates, may be

58 incorrectly estimated (Ribe 1982).

59 The lithospheric strength of tectonic plates reflects their resistance to vertical deformation

60 in response to geological loads over long-term $\left(>10^{5} \mathrm{yr}\right.$ ) geological timescales (Watts \& Burov

61 2003). This assumption allows the lithosphere to be modelled as the flexure of a thin, elastic

62 plate via the partial differential equation for the flexure of an orthotropic plate (Timoshenko \&

63 Woinowsky-Krieger 1959). This equation is usually used indirectly to calculate theoretical

64 admittance and coherence, which are then compared against observed ones to invert for the

65 non-uniform flexural rigidity (or effective elastic thickness, $T_{e}$ ) of the plate (Kirby

66 2014).Numerous studies have used $T_{e}$ to analyse lithospheric rheology and deformation 
67 (Pérez-Gussinyé et al. 2009; Chen et al. 2015; Ji et al. 2017, 2020; Lu et al. 2020). However, this

68 idealised term does not refer to an existing thickness or physical layer within the Earth, but

69 instead corresponds to the thickness of an ideal elastic plate that undergoes the same deformation

70 as the lithosphere under the same loads (Watts 2001). As $T_{e}$ is a periphrastical parameter for

71 understanding lithospheric rheology and deformation, directly modelling lithospheric flexure

72 should provide key insights into the nature of tectonic evolution and dynamics.

73 Here we use the classic lithospheric model with applied external and internal loads at the

74 surface and Moho, respectively, and assume that the compensation material is denser than the

75 mantle material beneath the Moho (Fig. 1). The density contrast between the compensation

76 material and mantle material beneath the Moho is set to $200 \mathrm{~kg} / \mathrm{m}^{3}$, based on the density contrast

77 between the uppermost and basal lithospheric mantle (Kaban et al. 2016). This is still an

78 idealised model that considers the vertical density variation in the lithosphere. Furthermore, we

79 obtain $T_{e}$ variations via the fan wavelet coherence method (Kirby \& Swain 2004, 2008) and the

80 Moho topography via a constrained gravity inversion method (Wu et al. 2017). We then employ

81 the finite-difference (FD) method to model lithospheric flexure. The errors associated with the

82 lithospheric flexure estimation in such a lithospheric model are mainly derived from the $T_{e}$ and

83 Moho errors. Synthetic modelling is then performed to analyse the influence of the $T_{e}$ and Moho

84 errors on the lithospheric flexure estimation. 


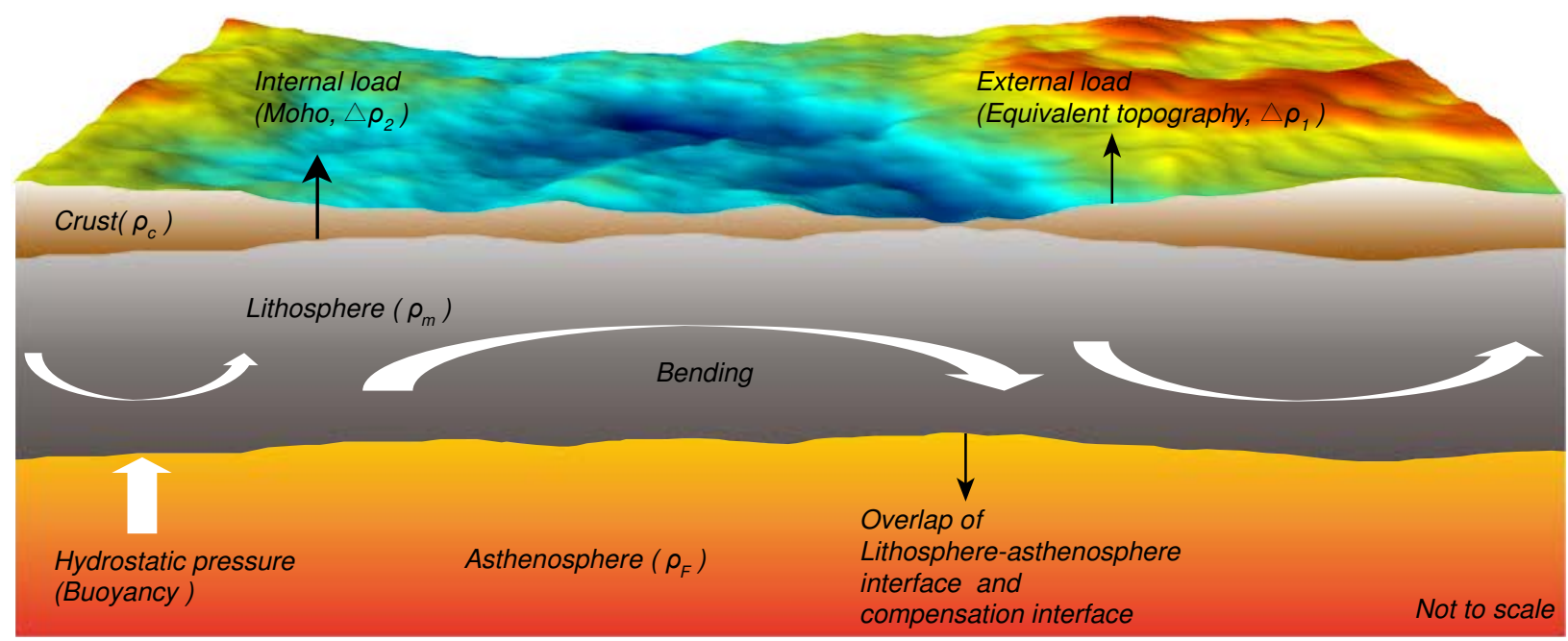

Fig. 1. Conceptual mechanical model of the lithosphere and asthenosphere.

\section{Methodology}

The key to calculating lithospheric flexure via the FD method is to obtain accurate spatial

92 distributions of the Moho and $T_{e}$. The Moho depth is usually recovered via gravity inversion (Wu

93 et al. 2017). There are currently two main methods for mapping the spatial variations in $T_{e}$ based

94 on the coherence between the Bouguer gravity anomaly and topography/bathymetry. One is the

95 multitaper method (McKenzie \& Fairhead 1997; Pérez-Gussinyé et al. 2004), and the other is fan

96 wavelet coherence method (Kirby \& Swain 2004, 2008). The characteristic flexural wavelength

97 is correlated with the strength of the lithosphere, and the flexural amplitude varies with both $T_{e}$

98 and the magnitude of the load (Watts 2001). These variations make it difficult to choose the

99 multitaper window size to recover $T_{e}$. Signals of features on a stronger lithosphere can be

100 truncated when the selected window size is too small, resulting in an artificially low $T_{e}$.

101 Conversely, $T_{e}$ can be blended across multiple features, with a potential bias toward the largest 
102 feature in the window, when the selected window size is too large (Pérez-Gussinyé et al. 2004,

103 2008; Kalnins \& Watts 2009). The fan wavelet coherence method can alleviate these issues by

104 allowing the $T_{e}$ features to be located at different wavelengths, and is employed to estimate $T_{e}$ in

105 this study.

106

107 Gravity inversion for Moho topography

108 Joint inversions that involve gravity measurements and other geophysical constraints are

109 generally employed to reduce the non-uniqueness of the best-fit models (Chappell \& Kusznir

110 2008; Bai et al. 2014; Ji et al. 2018). Here we perform a three-dimensional gravity inversion that

111 is constrained by seismic observations (Wu et al. 2017) to recover an accurate Moho topography.

112 The Moho topography that corresponds to the complete Bouguer gravity anomaly can be

113 expressed as $h(\mathbf{r})=h_{e}(\mathbf{r})+\Delta h(\mathbf{r})$, where $h_{e}(\boldsymbol{r})$ is the initial interface. The difference between

114 the Moho and initial interface can then be obtained by substituting this difference into the gravity

115 inversion equation (Oldenburg 1974):

$116 \quad F[\Delta h(\boldsymbol{r})]=-\frac{F[\Delta g]}{2 \pi G \rho} e^{k z_{0}}-\sum_{n=2}^{\infty} \frac{\boldsymbol{k}^{n-1}}{n !} F\left[\left\{h_{e}(\boldsymbol{r})+\Delta h(\boldsymbol{r})\right\}^{n}\right]-F\left[h_{e}(\boldsymbol{r})\right]$,

117 where $F[]$ is the Fourier transform, $\Delta g$ is the complete Bouguer gravity anomaly, $G$ is

118 Newton's gravitational constant, $\rho$ is the density contrast across the interface, $\boldsymbol{k}$ is the wave

119 vector of the transformed function, $\boldsymbol{r}$ is the entire $\mathrm{x}-\mathrm{y}$ plane and $z_{0}$ is the reference depth of 120 the density interface.

121 We largely follow the procedure outlined in $\mathrm{Wu}$ et al. (2017), except for the 
122 implementation of Eq. (1) to determine the interface difference during each iteration of the

123 inversion, to ensure that both the Moho depth and Bouguer gravity anomaly (Bg) satisfy the

124 inversion equation (Oldenburg 1974) after the Moho topography is recovered. The final Moho

125 topography is obtained iteratively until the interface difference between adjacent iteration steps

126 meets the error threshold.

128 Fan wavelet coherence method

129 The wavelet method for calculating the coherence between the topography and gravity

130 data was first proposed by Stark et al. (2003), who employed a Gaussian window function as the

131 transform kernel to estimate $T_{e}$ in southern Africa. The continuous wavelet transform offers the

132 ability to obtain the local phase and amplitude of the topography and gravity anomalies, whereas

133 the Fourier transform requires wavenumber averaging of the spectral estimates. The Gaussian

134 wavelet fails to reproduce the Fourier power spectrum exactly (Kirby 2005). Two-dimensional

135 Morlet wavelets, which are Gaussian-modulated complex exponential functions, can reproduce

136 the Fourier spectrum (Kirby \& Swain 2004). The spatial resolution of $T_{e}$ can be improved by

137 adjusting the central wavenumber of the Morlet wavelet (Kirby \& Swain 2011). Only the square

138 of the real component of the wavelet coherence needs to be employed to estimate $T_{e}$ (Kirby \&

139 Swain 2008, 2009). The squared real coherency can be expressed as a function of scale $s$ and

140 position $x$ : 
$141 \gamma_{o b s}^{2}(s, x)=\frac{\left|\operatorname{Re}\left\langle B_{s x \theta} H_{s x \theta}^{*}\right\rangle_{180}\right|^{2}}{\left\langle B_{s x \theta} B_{s x \theta}^{*}\right\rangle_{180}\left\langle H_{s x \theta} H_{s x \theta}^{*}\right\rangle_{180}}$,

142 where $B_{s x \theta}$ and $H_{s x \theta}$ represent the complex wavelet coefficients of the Bouguer gravity anomaly

143 and topography, respectively, the * indicates complex conjugation, and the angular brackets

144 denote azimuthal averaging performed over the entire $180^{\circ}$ azimuthal range. The predicted

145 squared-real coherency of the load-deconvolution method is (Kirby \& Swain 2009, 2011):

$146 \quad \gamma_{p r e}^{2}(s, x)=\frac{\left(\mu_{T} \kappa_{T}+\mu_{B} \kappa_{B} f^{2} r^{2}\right)^{2}}{\left(\mu_{T}^{2}+\mu_{B}^{2} f^{2} r^{2}\right)\left(\kappa_{T}^{2}+\kappa_{B}^{2} f^{2} r^{2}\right)}$,

147 where:

$148\left\{\begin{array}{l}\kappa_{B}=\Delta \rho_{2} / \varphi \\ \kappa_{T}=1-\Delta \rho_{1} / \varphi \\ \mu_{B}=2 \pi G \Delta \rho_{2}\left(1-\Delta \rho_{2} / \varphi\right) e^{-k Z_{m}} \\ \mu_{T}=2 \pi G \Delta \rho_{2}\left(1-\Delta \rho_{1} / \varphi\right) e^{-k Z_{m}} \\ \varphi=D k^{4} / g+\left(\rho_{m}-\rho_{f}\right) \\ \Delta \rho_{1}=\rho_{c}-\rho_{f} \\ \Delta \rho_{2}=\rho_{m}-\rho_{c} \\ D=\frac{E T e^{3}}{12\left(1-\sigma^{2}\right)}\end{array}\right.$,

$149 r=\left(\rho_{c}-\rho_{f}\right) /\left(\rho_{m}-\rho_{c}\right), \quad \rho_{c}$ and $\rho_{m}$ represent the crust and mantle densities, 150 respectively, $\rho_{f}$ represents either the air density (on land) or equivalent topography and 151 seawater density (in the ocean), $Z_{m}$ is the Moho depth, $\mathrm{g}$ is the gravitational acceleration, $E$ is the 152 Young's modulus, $\sigma$ is the Poisson's ratio, and $k \equiv \mathbf{k} \mid$ is the wavenumber modulus, which 153 can be replaced by the equivalent Fourier wavenumber in the fan-wavelet method (Kirby \& 154 Swain 2006). The final $T_{e}$ distributions are obtained by finding the $T_{e}$ that provides the minimum 
155 misfit between the observed and predicted coherencies at each grid point.

\section{Thin plate flexure}

For quick reference, we provide the key equations for estimating thin plate flexure, which

159 can be easily calculated via the approach of Kirby \& Swain (2008). We consider an elastic slab

160 model that involves only the initial external (at the surface) and internal (at the Moho) loads,

161 which are represented as $\left[\left(\rho_{c}-\rho_{f}\right) g h_{i}\right]$ and $\left[\left(\rho_{m}-\rho_{c}\right) g w_{i}\right]$, respectively. Four end-member

162 models are used here to illustrate the response of an elastic plate to an initial load with a

163 deflection amplitude $v$ (Fig. 2). The topography can be realistically considered the superposition

164 of these four models if we place the subsurface load at the Moho. The final deflection amplitude

$165 v$ can then be expressed as:

$166 v=h-h_{i}=w-w_{i}$.

167 Furthermore, we substitute the initial loads with Eq. (4) in the partial differential equation

168 for the flexure of an orthotropic plate (Timoshenko \& Woinowsky-Krieger 1959; Stark et al.

169 2003):

170

$D \nabla \nabla v+2 \frac{\partial D}{\partial x} \frac{\partial}{\partial x} \nabla v+2 \frac{\partial D}{\partial y} \frac{\partial}{\partial y} \nabla v+\nabla D \nabla v-(1-\sigma) \cdot\left\{\frac{\partial^{2} D}{\partial x^{2}} \frac{\partial^{2} v}{\partial y^{2}}-2 \frac{\partial^{2} D}{\partial x \partial y} \frac{\partial^{2} v}{\partial x \partial y}+\frac{\partial^{2} D}{\partial y^{2}} \frac{\partial^{2} v}{\partial x^{2}}\right\}$ $=-\left(\rho_{c}-\rho_{f}\right) g h-\left(\rho_{m}-\rho_{c}\right) g w$

171 where all variables are functions of the $(\mathrm{x}, \mathrm{y})$ position and $\nabla=\left(\partial^{2} / \partial x^{2}\right)+\left(\partial^{2} / \partial y^{2}\right)$ is the

172 Laplace operator. The solution to Eq. (5) via the FD method is shown in Appendix A. 
Before flexure

a

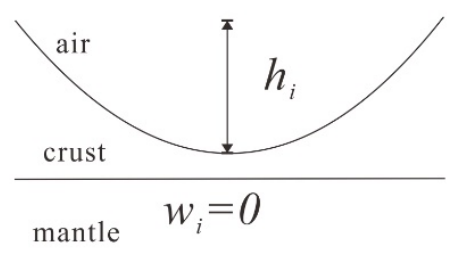

$h_{i}=0$

b

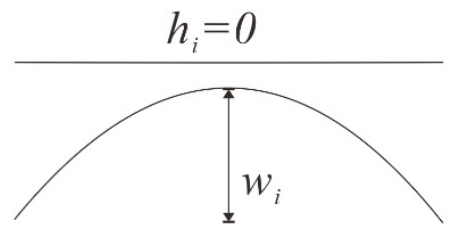

173
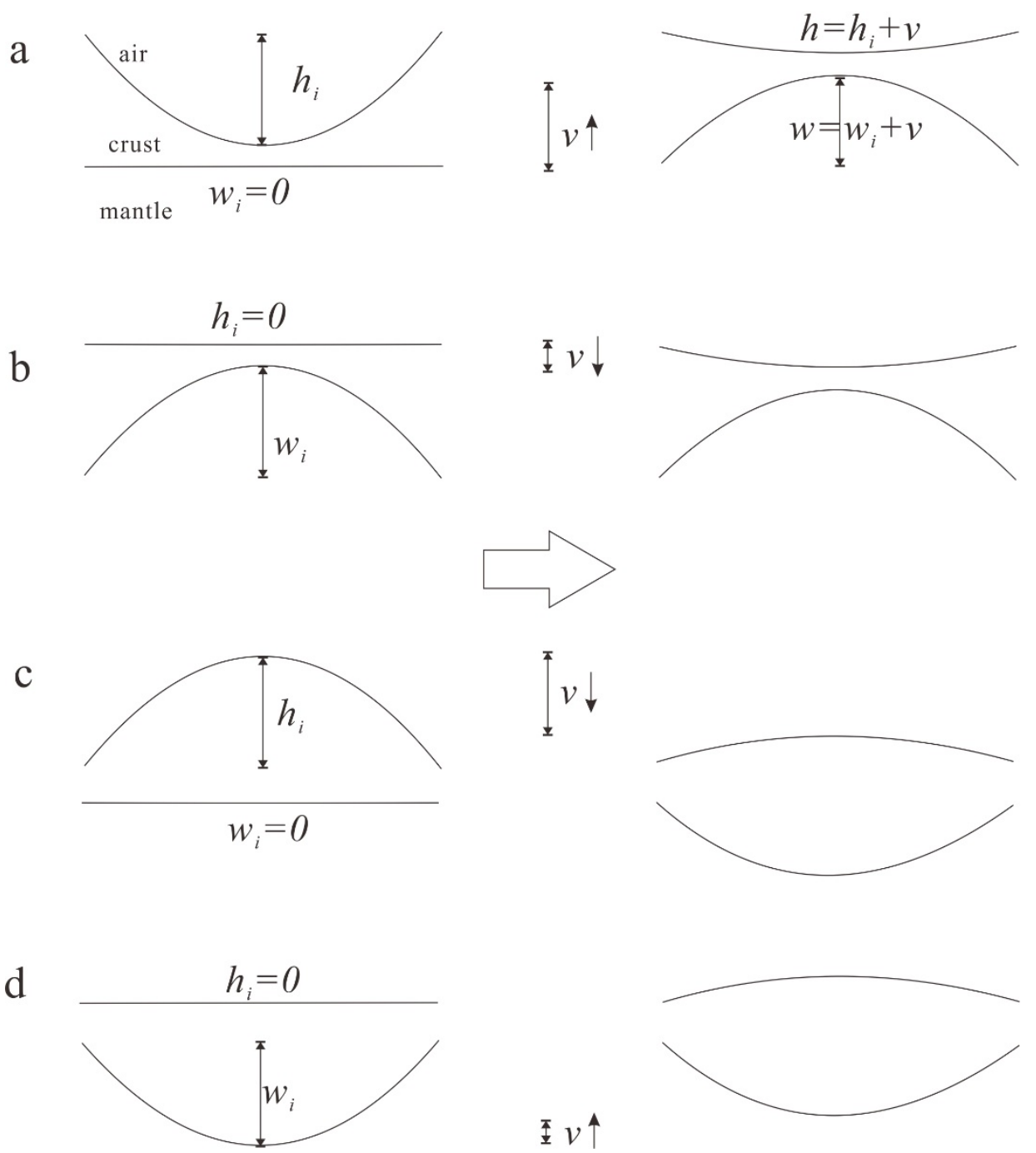

174 Fig. 2. Schematic cross sections illustrating the response of an elastic plate to four end-member

175 models. (a) Concave topography with an initial external (surface) load only. (b) Concave

176 topography with an initial internal (subsurface) load only. (c) Convex topography with an initial

177 external (surface) load only. (d) Convex topography with an initial internal (subsurface) load 178 only.

179 
182 a Winkler foundation. An elastic foundation is usually expressed as $\rho_{m} g v$ in linear elastic plate

183 theory. However, the deflection predicted via linear theory is always too high; this non-linearity

184 decreases with increasing plate thickness, such that plates with $T_{e}>20 \mathrm{~km}$ are only slightly

185 non-linear (Ribe 1982). This overestimated deflection should be suppressed in ocean settings

186 since $T_{e}$ is generally low in these settings. Here we extend the Banks et al. (2001) model,

187 whereby the internal load is confined to the crust, such that the entire lithosphere is modelled

188 with a lithospheric elastic foundation with higher density $\left(\rho_{F}\right)$ than that of the uppermost layer of

189 the mantle $\left(\rho_{m}\right)$. Equation (5) is then changed to:

190

$D \nabla \nabla v+2 \frac{\partial D}{\partial x} \frac{\partial}{\partial x} \nabla v+2 \frac{\partial D}{\partial y} \frac{\partial}{\partial y} \nabla v+\nabla D \nabla v-(1-\sigma) \cdot\left\{\frac{\partial^{2} D}{\partial x^{2}} \frac{\partial^{2} v}{\partial y^{2}}-2 \frac{\partial^{2} D}{\partial x \partial y} \frac{\partial^{2} v}{\partial x \partial y}+\frac{\partial^{2} D}{\partial y^{2}} \frac{\partial^{2} v}{\partial x^{2}}\right\}$

$+\left(\rho_{F}-\rho_{m}\right) g v=-\left(\rho_{c}-\rho_{f}\right) g h-\left(\rho_{m}-\rho_{c}\right) g w$

191 and the first term in Eq. (A2) is changed to:

$192 V_{i, j}:(3-2 \sigma)\left(D_{i-1, j}+D_{i+1, j}+D_{i, j-1}+D_{i, j+1}\right)+8(1+\sigma) D_{i, j}+\left(\rho_{F}-\rho_{m}\right) g v \lambda^{4}$.

193 The main advantages of this model are:

194 1. The overestimated deflection of the lithosphere predicted via linear theory can be suppressed;

195 2. The density of the mantle usually increases with depth, so the model fits real data better in the

196 framework of lithospheric-scale deflection;

197 3. The main inversion function (Eq. (5)) in such a model can be converted to Eq. (6), which can

198 be considered as a forward equation with a small Winkler foundation, thereby ensuring that

199 stable calculation results are always obtainable. 


\section{Synthetic modelling}

202 Synthetic modelling is commonly used to test the accuracy of the wavelet method (Stark et

203 al. 2003; Kirby and Swain, 2004, 2008). Random fractal initial loads and $T_{e}$ models are used as

204 inputs to the flexural equation, which outputs the final surface topography $(h)$ and Moho

205 topography $(w)$. We follow the same approach in our synthetic modelling. We employ Eq. (6) in

206 the inversion since it is a thorough rearrangement of the flexural equation (Eq. (11)) in Kirby and

207 Swain (2009), with the final topography $(h)$ and a random fractal initial internal load $\left(w_{i}\right)$ as

208 inputs.

209 The equivalent topography, $T_{e}$ and Moho topography, are required to estimate lithospheric

210 flexure. The equivalent topography can be specifically calculated using a global elevation model,

211 sediment thickness model and sediment thickness-density conversion formula (e.g., Sclater \&

212 Christie 1980; Ji et al. 2020), such that this random fractal initial load $\left(h_{i}\right)$ and flexure $(v)$ derived

213 topography $(h)$ can be used in the synthetic modelling. The influences of both the recovered $T_{e}$

214 errors and inverted Moho errors on the FD-derived lithospheric flexure are investigated to

215 determine how these inputs shape the model results.

216

\section{Model Generation}

218 We follow the synthetic modelling procedure of Macario et al. (1995), and use the

219 mid-point displacement method (Peitgen \& Saupe 1988) to generate two-dimensional fractal 
220 Brownian surfaces that represent the initial external (surface) and internal (subsurface) loads. A

221 fractal dimension of 2.5 is used for the surface (Fig. 3a) and subsurface loads (Fig. 3b), as well as

222 the $T_{e}$ model (Fig. 3c). The grids consist of $255 \times 255$ points at a $20-\mathrm{km}$ spacing and are scaled to

223 possess a realistic amplitude. Furthermore, the $T_{e}$ grid is low-pass filtered with a cut-off

224 wavelength of $150 \mathrm{~km}$. We choose a central wavenumber of 5.336 in the subsequent fan wavelet

225 coherence inversion since we place greater importance on the $T_{e}$ accuracy than its spatial

226 resolution. We do not set a constant $F$ (loading ratio), as in Kirby and Swain (2008). Although

227 this approach may go against Forsyth's fourth assumption about the proportionality of the power

228 spectral densities of the initial loads (Simons \& Olhede 2013), the feasibility of the $T_{e}$ inversion

229 with multiple varying $F$ interfaces via the fan wavelet coherence method has already been tested

230 by Kirby and Swain (2009). The topography (Fig. 3d), Moho (Fig. 3e) and lithospheric flexure

231 models (Fig. 3f) are obtained by applying the FD method to Eq. (6). The Moho interface is then

232 used to obtain the forward Bouguer gravity anomaly (Fig. 4), with the relevant parameters listed

233 in Table 1. The Moho inherits high-frequency information from the initial subsurface. However,

234 the modelled Bouguer gravity anomaly may suffer from signal degradation due to upward

235 continuation of the signal since the observation surface is much higher than the Moho interface,

236 resulting in attenuation of this high-frequency information.

Table 1. Symbols and employed values for the model constants (revised from Kirby \& Swain 2008).

\begin{tabular}{llll}
\hline \multicolumn{1}{c}{ Constant } & Symbol & \multicolumn{1}{c}{ Value } & Units \\
\hline $\begin{array}{l}\text { Young's modulus } \\
\text { Newtonian }\end{array}$ & $E$ & 100 & $\mathrm{GPa}$ \\
$\begin{array}{l}\text { gravitational constant } \\
\text { Poisson's ratio }\end{array}$ & $G$ & $6.67259 \times 10^{-11}$ & $\mathrm{~m}^{3} \cdot \mathrm{kg}^{-1} \cdot \mathrm{s}^{-2}$ \\
Acceleration due to & $g$ & 0.25 & \\
\hline
\end{tabular}




\begin{tabular}{llll}
\hline gravity & & & \\
Mean Moho depth & $z_{m}$ & 40 & $\mathrm{~km}$ \\
Crustal density & $\rho_{c}$ & 2750 & $\mathrm{~kg} \cdot \mathrm{m}^{-3}$ \\
$\begin{array}{l}\text { Mantle density } \\
\text { Compensation }\end{array}$ & $\rho_{m}$ & 3200 & $\mathrm{~kg} \cdot \mathrm{m}^{-3}$ \\
Mantle density & $\rho_{F}$ & 3400 & $\mathrm{~kg} \cdot \mathrm{m}^{-3}$ \\
\hline
\end{tabular}

238 

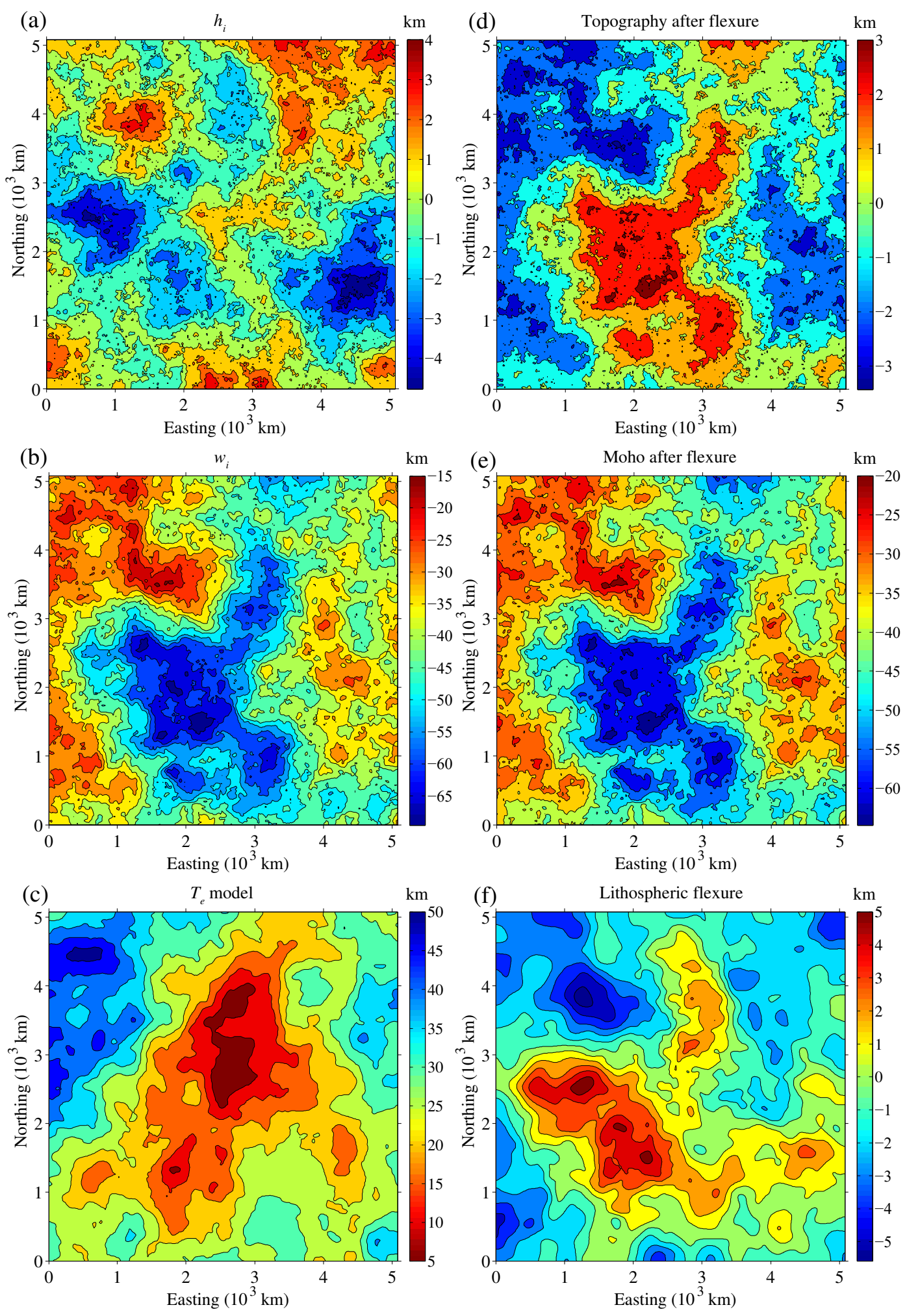

241 Fig. 3. (a) initial surface $\left(h_{i}\right)$, (b) initial subsurface $\left(w_{i}\right)$, (c) model, (d) topography after flexure,

(e) Moho after flexure, and (f) lithosphere flexure. 


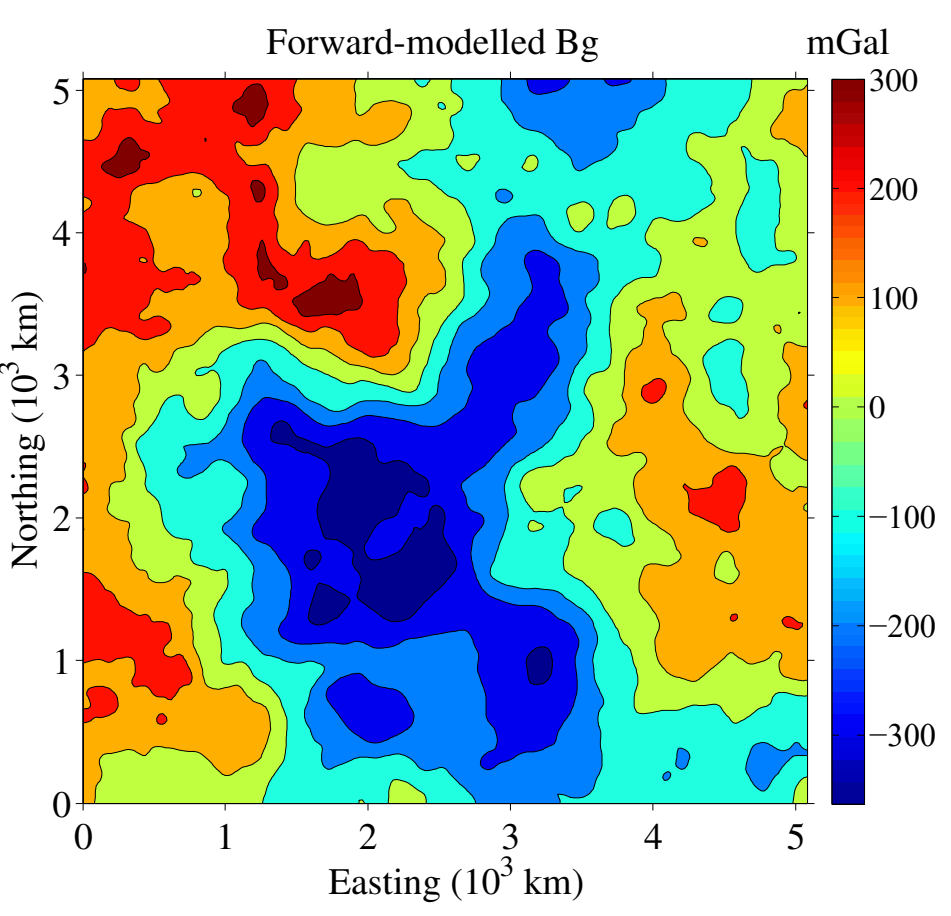

244 Fig. 4. Forward-modelled Bouguer gravity anomaly (Bg).

\section{Effect of $T_{e}$ errors}

247 The fan wavelet coherence method is employed to invert for $T_{e}$ using the generated surface 248 topography, Moho topography and forward-modelled Bouguer anomaly grids (Fig. 5a), and to 249 calculate its associated errors (Fig. 5b). This $T_{e}$ inversion recovers well the main $T_{e}$ features in 250 the $T_{e}$ model. The errors are randomly distributed across the entire map, but the trend of the local 251 errors is consistent with the $T_{e}$ gradient belts. This consistency is due mainly to the resolution of 252 the transition wavelets, as well as two other adverse factors: (1) the decoupling assumption and 253 (2) the assumption of uniform $T_{e}$ in the loading equations (Kirby \& Swain 2008).

254 We then used the generated topography, Moho topography and inverted $T_{e}$ grids to estimate 255 (Eq. (6)) the lithospheric flexure (Fig. 6a) and the associated errors (Fig. 6b). The 256 long-wavelength component of the two flexure maps is basically the same (Figs $3 \mathrm{f}$ and 6a), and 257 the amplitudes of the flexure errors (Fig. 6b) are up to one order of magnitude smaller than the $T_{e}$ 258 errors (Fig. 5b). This means that the inverted flexure is insensitive to the $T_{e}$ errors. The $T_{e}$ 
error-induced flexure errors also exhibit a rippling pattern due to the deflection of a higher $T_{e}$

260 plate possessing a lower amplitude and slower amplitude decay rate, although such a rippling

261 pattern is truncated and/or deformed by the attitudes of $T_{e}$ and total load. Furthermore, the range

262 of the rippling pattern is affected by the $T_{e}$ values and load amplitude, although it has a higher

263 correlation with the $T_{e}$ values in this synthetic modelling study, as the rippling pattern is

264 obviously broader in the high $T_{e}$ regions.

(a)

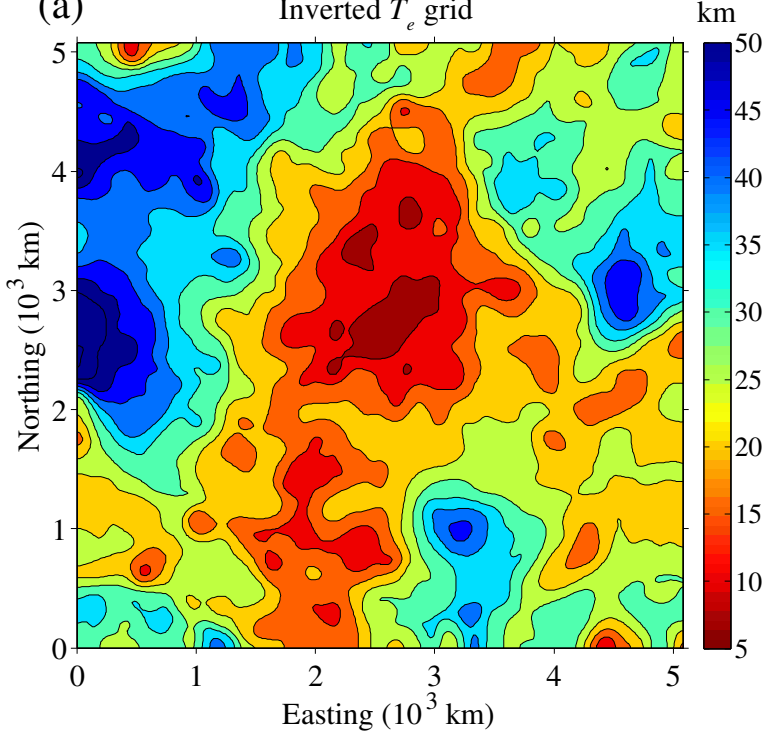

(b) $\quad T_{e}$ errors due to the inversion

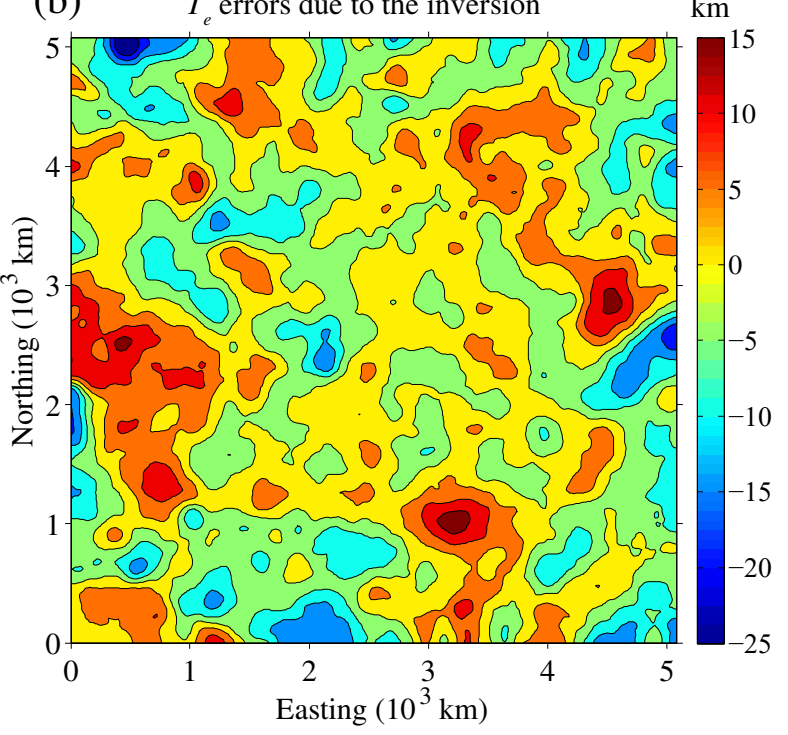

266 Fig. 5. (a) Inverted $T_{e}$ grid. (b) $T_{e}$ errors due to the inversion.

(a)

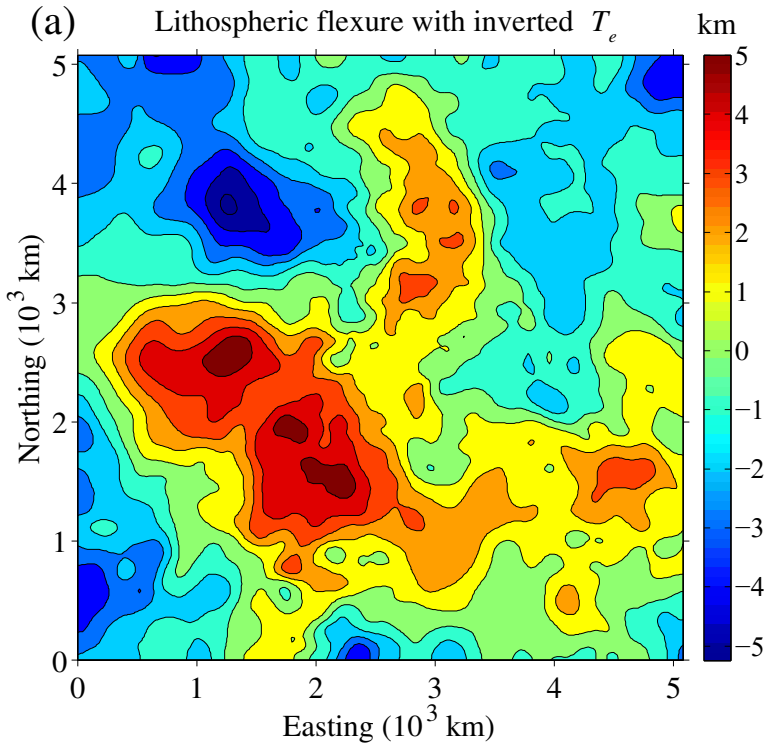

(b) Lithospheric flexure errors with inverted $T_{e} \quad \mathrm{~km}$

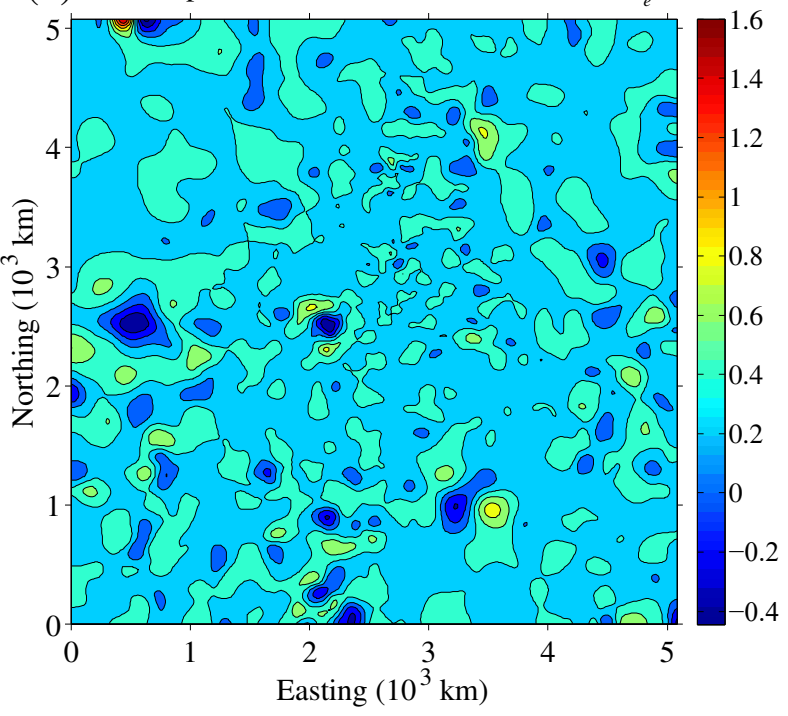

Fig. 6. (a) Lithospheric flexure using the inverted $T_{e}$ grid. (b) Lithospheric flexure errors for the model inversion using the inverted $T_{e}$ grid. 


\section{Effect of Moho errors}

272 Bouguer gravity anomaly reflects the long-wavelength Moho information. It follows that

273 the short-wavelength component of the flexure-derived Moho will be the main source of error

274 (Fig. 7b) when we use the Bouguer anomaly to invert for the Moho topography (Fig. 7a).

275 Although the maximum Moho error is $6 \mathrm{~km}$, the Moho inversion yields reliable results as the

276 root-mean-square error is only $0.91 \mathrm{~km}$. Furthermore, the even distribution of the Moho errors

277 provides insights into how the Moho inversion errors impact the flexure errors.

278 We also used the generated topography, $T_{e}$ model and recovered (inverted) Moho

279 topography to estimate (Eq. (6)) the lithospheric flexure (Fig. 8a) and the associated errors (Fig.

280 8b). A comparison of the Moho and flexure results yields the following findings. 1) The Moho

281 inversion errors are distributed evenly across the entire region, whereas the main flexure errors

282 occur in the low $T_{e}$ regions. 2) The Moho errors tend to induce flexure errors with similar

283 magnitudes but opposite signs (see the white rectangles in Figs $7 \mathrm{~b}$ and $8 \mathrm{~b}$ ). 3) There seems to be

284 a linear attenuation coefficient of the form $-\left(\rho_{F}-\rho_{m}\right) /\left(\rho_{m}-\rho_{c}\right)$ between the large flexure

285 errors and corresponding Moho errors. 4) The plate still acts like a low-pass filter to the Moho

286 disturbance, even in the low $T_{e}$ regions, with an increase in the intensity of filtering where there

287 is an increase in the $T_{e}$ values.

288 Although the flexure error in the low $T_{e}$ regions, e.g., oceanic lithosphere, is sensitive to the

289 Moho disturbance, this method is still suitable for investigations of the oceanic lithosphere. The 
290 reference depth of the oceanic Moho is shallow, which may allow us to retain more

291 short-wavelength information, such that more accurate inversion results can be obtained. And the

292 Moho disturbance is attenuated by an attenuation coefficient as well as the lithosphere strength

293 as it propagates into the lithospheric flexure error. In addition, the FD method-derived flexure is

294 suited for Airy isostasy theory, even in the extremely low $T_{e}$ regions.

295
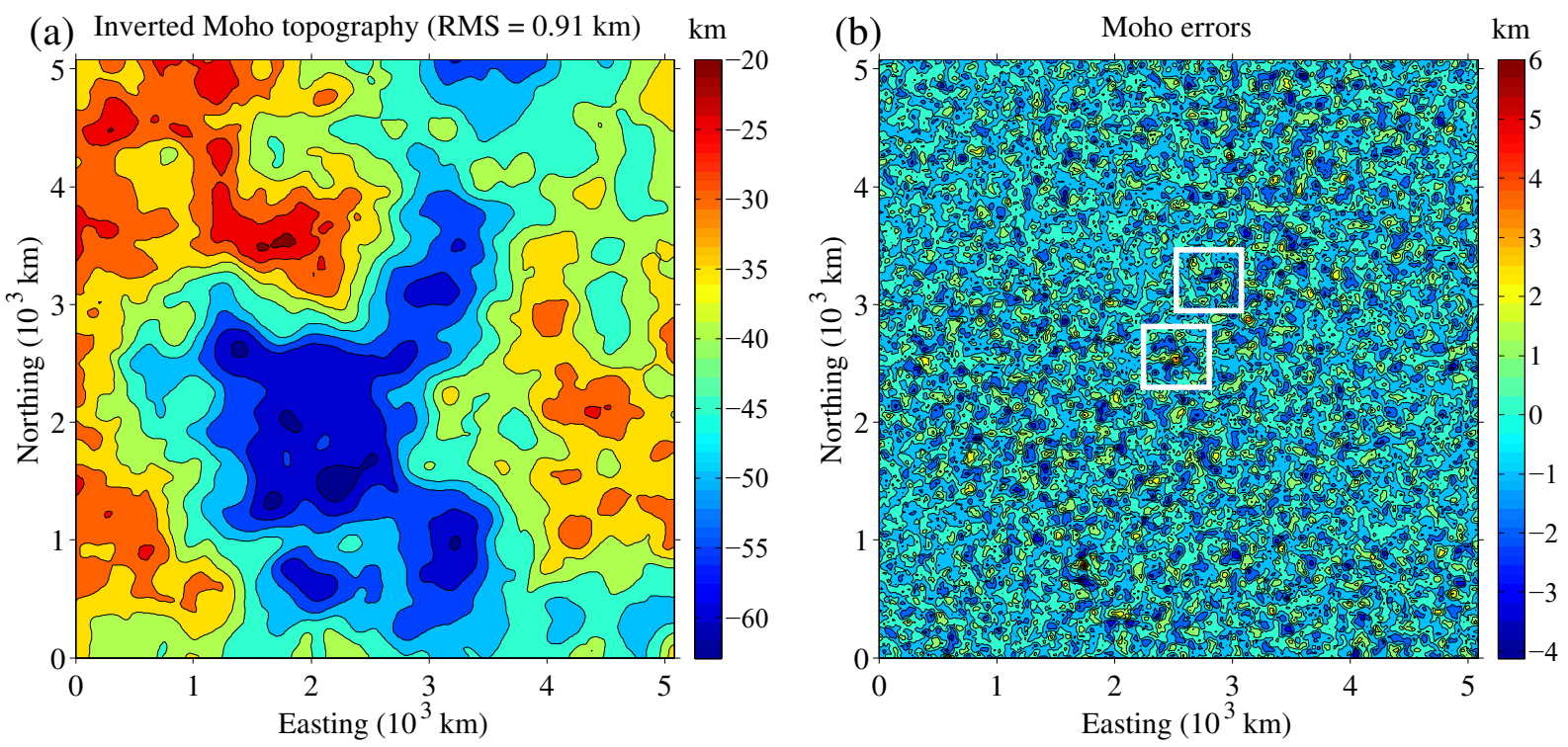

296 Fig. 7. (a) Inverted Moho topography with the forward-modelled Bouguer anomaly (Bg). (b)

297 Moho errors. 

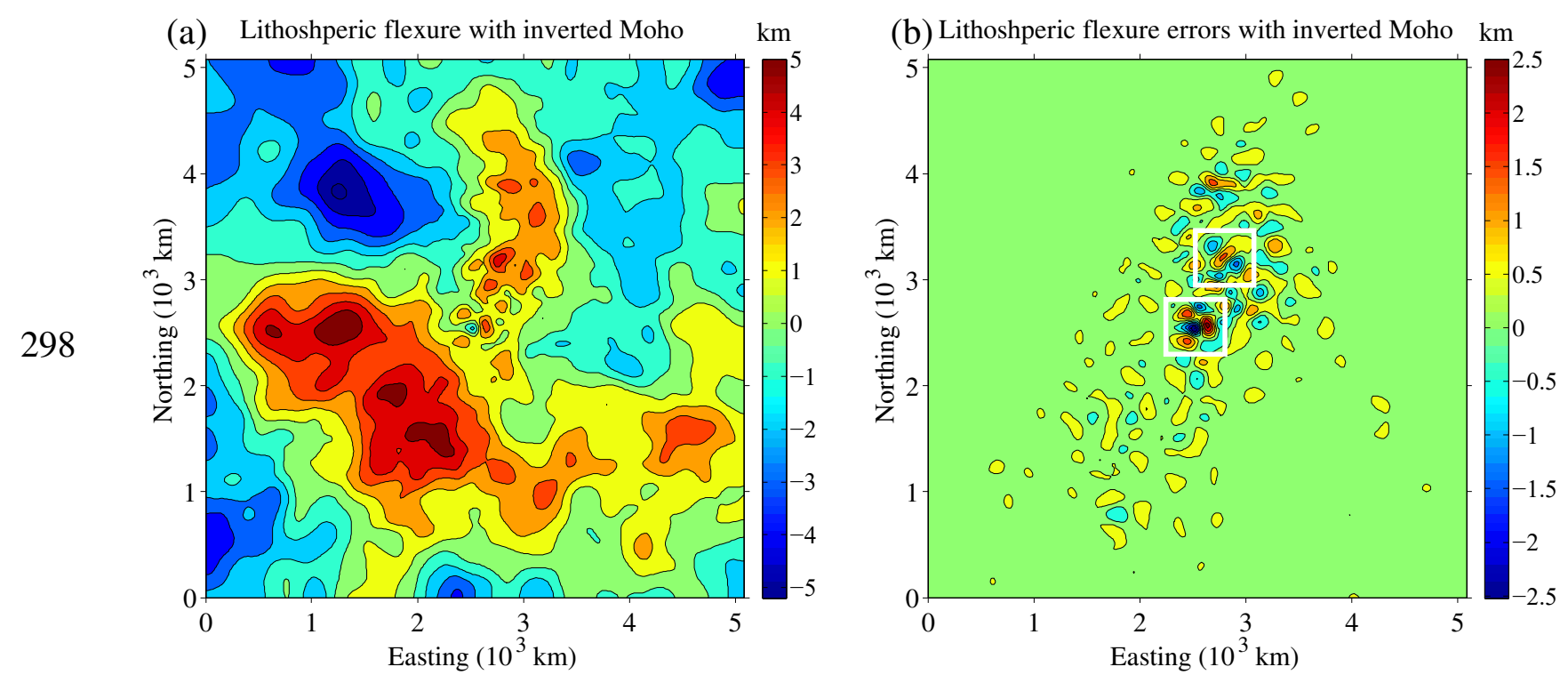

299 Fig. 8. (a) Lithospheric flexure using the inverted Moho values. (b) Lithospheric flexure errors

300 for the model inversion using the inverted Moho values.

\section{Integrated effects of the $T_{e}$ and Moho errors}

Neither $T_{e}$ nor the Moho can be recovered with absolute accuracy using real datasets. We

304 therefore investigated the integrated effects of the $T_{e}$ and Moho errors on the estimated

305 lithospheric flexure errors to explicate the sources of the flexure errors. We used the generated

306 topography, recovered $T_{e}$ and inverted Moho topography to invert (Eq. (6)) for the lithospheric

307 flexure (Fig. 9a) and calculate their associated errors (Fig. 9b). The long-wavelength component

308 of the lithospheric flexure is still well recovered, indicating that the FD method is stable when an

309 integrated disturbance is applied. The lithospheric flexure errors are dominated by the $T_{e}$ errors

310 in the high $T_{e}$ regions (Figs $6 \mathrm{~b}$ and $9 \mathrm{~b}$ ). Correspondingly, the flexure errors are dominated by the

311 Moho errors in the low $T_{e}$ regions, although the amplitudes of the flexure errors have been 
312 somehow changed in the low $T_{e}$ regions (Figs $8 \mathrm{~b}$ and $9 \mathrm{~b}$ ).

313

314
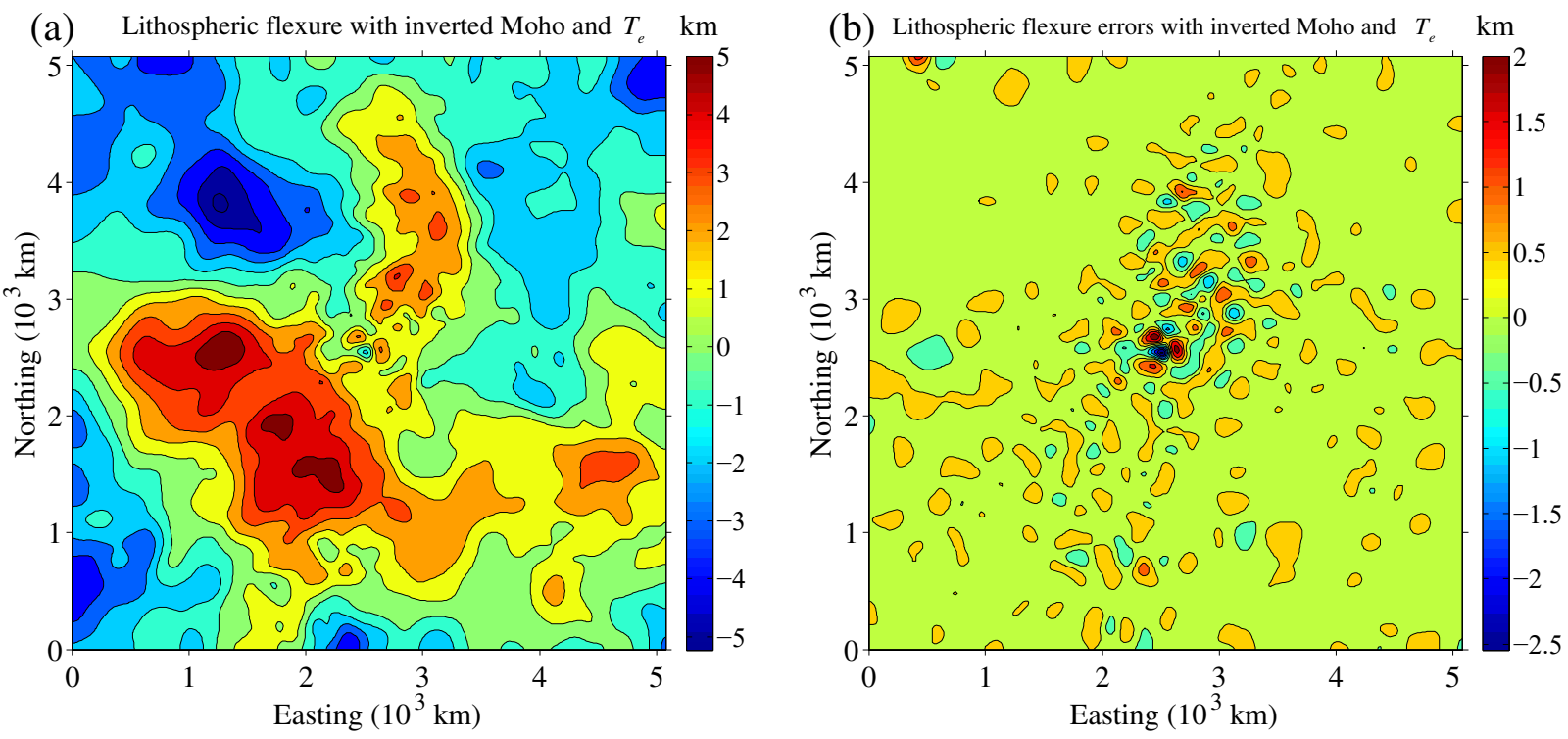

315 Fig. 9. (a) Lithospheric flexure using the inverted Moho and $T_{e}$ values. (b) Lithospheric flexure

316 errors from the model inversion using the inverted Moho and $T_{e}$ values.

\section{Conclusions}

319 Here we employed the classic lithospheric model with an applied external load at the

320 surface and internal load at the Moho, and assumed that the compensation material was denser

321 than the mantle material beneath the Moho, in an attempt to estimate lithospheric flexure. The

322 resultant lithospheric model is closer to the actual lithospheric structure, with effective

323 suppression of the overestimated lithospheric deflection predicted via linear theory, and

324 conversion of the main lithospheric flexure inversion function (Eq. (5)) into a forward equation

325 with a small Winkler foundation (Eq. (6)). This lithospheric model, which based on $T_{e}$ estimates 
326 from the fan wavelet coherence method and gravity-derived Moho topography, yields a

327 finite-difference solution of the partial differential equation that recalibrates the lithospheric

328 flexure with high accuracy. Our main conclusions are as follows:

329 1. The inverted flexure is insensitive to $T_{e}$ errors, and the $T_{e}$ error-induced flexure errors 330 exhibit a rippling pattern.

331 2. The Moho error-induced flexure errors mainly occur in the low $T_{e}$ regions. The Moho 332 disturbance is attenuated by an attenuation coefficient of the form $-\left(\rho_{F}-\rho_{m}\right) /\left(\rho_{m}-\rho_{c}\right)$

333 and by the lithospheric strength as Moho disturbance propagates into the lithosphere 334 flexure error.

335 3. The flexure errors in the low and high $T_{e}$ regions are dominated by the Moho and $T_{e}$ errors, 336 respectively.

338 Availability of Data and Materials The datasets that were used, analysed and produced during

339 the current study are available from the corresponding author upon reasonable request.

\section{Competing Interests}

342 The authors declare that they have no competing interests.

344 Funding

345 This work is supported by the Second Institute of Oceanography, Ministry of Natural Resources

346 (Grant No. JT1601), the National Natural Science Foundation of China (Grant Nos. 42076078, 347 42076047, 41676037, 91858213, 41776057, and 41761134051), the National Program on Global 348 Change and Air Sea Interaction (Grant No. GASI-GEOGE-05) and the Institute of Crustal 
349 Dynamics, China Earthquake Administration (Grant No. ZDJ2019-30).

350

\section{Authors' Contributions}

352 MX processed and interpreted the data, produced the figures and wrote the main manuscript text.

$353 \mathrm{ZW}$ assisted in the gravity inversion. FJ assisted in the application of the fan wavelet coherence

354 method. AR, CL and JG contributed to the Lithospheric model discussion and manuscript 355 revisions.

356

357 Acknowledgements

358 Not applicable.

359 
References

361 Bai Y, Williams SE, Müller RD, Liu Z, Hosseinpour M (2014) Mapping crustal thickness using marine gravity data: Methods and uncertainties. Geophysics 79:2, G27-G36. https://doi.org/10.1190/geo2013-0270.1

Banks RJ, Francis SC, Hipkin RG (2001) Effects of loads in the upper crust on estimates of the elastic thickness of the lithosphere. Geophys J Int 145:291-299. https://doi.org/10.1046/j.0956-540x.2001.01380.x

Braitenberg C, Ebbing J, Gotze H-J (2002) Inverse modelling of elastic thickness by convolution method - the eastern Alps as a case example. Earth Planet Sci Lett 202:387-404. https://doi.org/10.1016/S0012-821X(02)00793-8

Burov EB, Diament M (1992) Flexure of the continental lithosphere with multilayered rheology. Geophys J Int 109:449-468. https://doi.org/10.1111/j.1365-246X.1992.tb00107.x

Chen B (2013) The effective elastic thickness over China and surroundings and its lithosphere dynamic implication, Doctoral thesis, China University of Geosciences, Wuhan. (in Chinese)

Chen B, Kaban MK, El Khrepy S, Al-Arifi N (2015) Effective elastic thickness of the Arabian plate: Weak shield versus strong platform. Geophys Res Lett 42:3298-3304. https://doi.org/10.1002/2015GL063725

Dorman LM, Lewis BTR (1970) Experimental isostasy: 1. Theory of the determination of the Earth's isostatic response to a concentrated load. J Geophys Res 75:3357-3365.

Dorman LM, Lewis BTR (1972) Experimental isostasy: 3. Inversion of the isostatic Green function and https://doi.org/10.1029/JB075i017p03357

385 Forsyth DW (1985) Subsurface loading and estimates of the flexural rigidity of continental lithosphere, J. 
Geophys. Res., 90:12623-12632. https://doi.org/10.1029/JB090iB14p12623

Ghali A, Neville AM, Brown TG (1989) Structural analysis: a unified classical and matrix approach.

Ji F, Gao J, Li F, Shen Z, Zhang Q, Li Y (2017) Variations of the effective elastic thickness over the Ross Sea and Transantarctic Mountains and implications for their structure and tectonics. Tectonophysics 717:127-138. https://doi.org/10.1016/j.tecto.2017.07.011

Ji F, Li F, Gao J-Y, Zhang Q, Hao W-F (2018) 3-D density structure of the Ross Sea basins, West Antarctica from constrained gravity inversion and their tectonic implications. Geophys J Int 215:1241-1256. https://doi.org/10.1093/gji/ggy343

Ji F, Zhang Q, Zhou X, Bai Y, Li Y (2020) Effective elastic thickness of Zealandia and its implications for lithospheric deformation. Gondwana Res. 86:46-59. https://doi.org/10.1016/j.gr.2020.05.008

Kaban MK, Stolk W, Tesauro M, El Khrepy S, Al-Arifi N, Beekman F, Cloetingh SAPL (2016) 3D density model of the upper mantle of Asia based on inversion of gravity and seismic tomography data. Geochem Geophys Geosyst 17:4457-4477. https://doi.org/10.1002/2016GC006458

Kalnins LM, Watts AB (2009) Spatial variations in effective elastic thickness in the Western Pacific Ocean and their implications for Mesozoic volcanism. Earth Planet Sci Lett 286:89-100. https://doi.org/10.1016/j.eps1.2009.06.018

Kirby JF, Swain CJ (2004) Global and local isostatic coherence from the wavelet transform. Geophys Res Lett 31:L24608. https://doi.org/10.1029/2004GL021569

Kirby JF (2005) Which wavelet best reproduces the Fourier power spectrum? Comput Geosci 31:846864. https://doi.org/10.1016/j.cageo.2005.01.014

Kirby JF, Swain CJ (2006) Mapping the mechanical anisotropy of the lithosphere using a 2D wavelet coherence, and its application to Australia. Phys Earth Planet Inter 158:122-138. https://doi.org/10.1016/j.pepi.2006.03.022

Kirby JF, Swain CJ (2008) An accuracy assessment of the fan wavelet coherence method for elastic thickness estimation. Geochem Geophys Geosyst 9:Q03022. https://doi.org/10.1029/2007GC001773

Kirby JF, Swain CJ (2009) A reassessment of spectral Te estimation in continental interiors: The case of 
414 Kirby JF, Swain CJ (2011) Improving the spatial resolution of effective elastic thickness estimation with 415 the fan wavelet transform. Comput Geosci 37:1345-1354. $416 \quad$ https://doi.org/10.1016/j.cageo.2010.10.008

417 Kirby JF (2014) Estimation of the effective elastic thickness of the lithosphere using inverse spectral 418 methods: The state of the art. Tectonophysics 631:87-116. 419 https://doi.org/10.1016/j.tecto.2014.04.021

420 Lewis BTR, Dorman LM (1970a) Correction to paper by Brian T. R. Lewis and LeRoy M. Dorman 421 'Experimental isostasy: 2 An isostatic model for the U.S.A. derived from gravity and topographic data'. J Geophys Res 75:4482-4482. https://doi.org/10.1029/JB075i023p04482

423 Lewis BTR, Dorman LM (1970b) Experimental isostasy: 2. An isostatic model for the U.S.A. derived 424 from gravity and topographic data. J Geophys Res 75:3367-3386. https://doi.org/10.1029/JB075i017p03367

Lu Z, Li C-F, Zhu S, Audet P (2020) Effective elastic thickness over the Chinese mainland and surroundings estimated from a joint inversion of Bouguer admittance and coherence. Phys Earth Planet Inter 301:106456. https://doi.org/10.1016/j.pepi.2020.106456

Macario A, Malinverno A, Haxby WF (1995) On the robustness of elastic thickness estimates obtained using the coherence method. J Geophys Res Atmos 100:15163-15172. https://doi.org/10.1029/95JB00980

432 McKenzie D (2003) Estimating Te in the presence of internal loads. J Geophys Res Solid Earth, 433 108:2438, B9. https://doi.org/10.1029/2002JB001766

434 McKenzie D, Fairhead D (1997) Estimates of the effective elastic thickness of the continental lithosphere 435 from Bouguer and free air gravity anomalies. J Geophys Res Solid Earth 102:27523-27552, B12. 436 https://doi.org/10.1029/97JB02481

437 McNutt M (1980) Implications of regional gravity for state of stress in the Earth's crust and upper mantle. J Geophys Res Solid Earth 85:6377-6396. https://doi.org/10.1029/JB085iB11p06377

439 Oldenburg DW (1974) The inversion and interpretation of gravity anomalies. J Geophysics 39:526-536. 
https://doi.org/10.1190/1.1440444

441 Pérez-Gussinyé M, Lowry AR, Watts AB, Velicogna I (2004) On the recovery of effective elastic

442 thickness using spectral methods: examples from synthetic data and from the Fennoscandian Shield.

$443 \quad$ J Geophys Res Solid Earth 109:B10409. https://doi.org/10.1029/2003JB002788

444 Pérez-Gussinyé M, Lowry A, Phipps Morgan J, Tassara A (2008) Effective elastic thickness variations

445 along the Andean margin and their relationship to subduction geometry. Geochem Geophys Geosyst

446 9:Q02003. https://doi.org/10.1029/2007GC001786

447 Pérez-Gussinyé M, Metois M, Fernández M, Vergés J, Fullea J, Lowry AR (2009) Effective elastic 448 thickness of Africa and its relationship to other proxies for lithospheric structure and surface 449 tectonics. Earth Planet Sci Lett 287:152-167. https://doi.org/10.1016/j.epsl.2009.08.004

450 Peitgen H-O, Saupe D (eds) (1988) The science of fractal images. Springer-Verlag, New York.

451 Ribe NM (1982) On the interpretation of frequency response functions for oceanic gravity and 452 bathymetry. Geophys J Int 70:273-294. https:doi.org/10.1111/j.1365-246X.1982.tb04968.x

453 Sclater JG, Christie P (1980) Continental stretching: an explanation of the post-mid-cretaceous subsidence 454 of the central north sea basin. J Geophys Res Solid Earth, 85:6377-6396, B11. 455 https://doi.org/10.1029/JB085iB11p06377.

456 Simons FJ, Olhede SC (2013) Maximum-likelihood estimation of lithospheric flexural rigidity, 457 initial-loading fraction and load correlation, under isotropy. Geophys J Int 193:1300-1342. $458 \quad$ https://doi.org/10.1093/gji/ggt056

459 Stark CP, Stewart J, Ebinger CJ (2003) Wavelet transform mapping of effective elastic thickness and plate 460 loading: Validation using synthetic data and application to the study of southern African tectonics. J Geophys Res Solid Earth 108:B12. https://doi.org/10.1029/2001JB000609

462 Timoshenko SP, Woinowsky-Krieger S (1959) Theory of plates and shells, 2nd edn. McGraw-Hill, New $463 \quad$ York.

464 Watts AB, Burov EB (2003) Lithospheric strength and its relationship to the elastic and seismogenic layer 465 thickness. Earth Planet Sci Lett 213:113-131. https://doi.org/10.1016/S0012-821X(03)00289-9

466 Watts AB (2001) Isostasy and Flexure of the Lithosphere. Cambridge University Press, New York. 
467 Wu Z, Gao J, Ding W, Shen Z, Zhang T, Yang, C (2017) The Moho depth of the South China Sea basin 468 from three-dimensional gravity inversion with constraint points and its characteristics. Chin J 469 Geophys 60:368-383. https://doi.org/10.1002/cjg2.30053

470 Zhang J, Sun Z, Xu M, Yang H, Zhang Y, Li F (2018) Lithospheric 3-D flexural modelling of subducted $471 \quad$ oceanic plate with variable effective elastic thickness along Manila Trench. Geophys J Int 215:2071472 2092. https://doi.org/10.1093/gji/ggy393

473

474 


\section{Appendix A: Finite-difference method}

The FD solution in Eq. (5) is mainly from Chen (2013), but we use the final loads instead of

477 the initial loads on the right side of the equation. Equation (5) can be further simplified to:

478 $\nabla(D \nabla v)-(1-\sigma) \cdot\left\{\frac{\partial^{2} D}{\partial x^{2}} \frac{\partial^{2} v}{\partial y^{2}}-2 \frac{\partial^{2} D}{\partial x \partial y} \frac{\partial^{2} v}{\partial x \partial y}+\frac{\partial^{2} D}{\partial y^{2}} \frac{\partial^{2} v}{\partial x^{2}}\right\}$ $=-\left(\rho_{c}-\rho_{f}\right) g h-\left(\rho_{m}-\rho_{c}\right) g w$

The differential operations in Eq. (A1) are approximated using central difference operators. A schematic diagram of the central difference grid (Gahli \& Neville 2017) is shown in Fig. A1, whereby a square grid is adopted, such that $d x=d y$. The corresponding central difference operators for the first-order, second-order and Laplace differential operations are shown in Fig. 483 A2.

The approximation to the differential operations is then undertaken with the central 485 difference operators, followed by formula expansion and combination. The following coefficients of the indicated $v_{i, j}$ terms for an isotropic plate can then be obtained: 


$$
\left\{\begin{aligned}
V_{i, j} & :(3-2 \sigma)\left(D_{i-1, j}+D_{i+1, j}+D_{i, j-1}+D_{i, j+1}\right)+8(1+\sigma) D_{i, j} \\
V_{i+1, j} & :-2(1+\sigma) D_{i, j}-4 D_{i+1, j}-(1-\sigma)\left(D_{i, j-1}+D_{i, j+1}\right) \\
V_{i-1, j} & :-2(1+\sigma) D_{i, j}-4 D_{i-1, j}-(1-\sigma)\left(D_{i, j-1}+D_{i, j+1}\right) \\
V_{i, j+1} & :-2(1+\sigma) D_{i, j}-4 D_{i, j+1}-(1-\sigma)\left(D_{i-1, j}+D_{i+1, j}\right) \\
V_{i, j-1} & :-2(1+\sigma) D_{i, j}-4 D_{i, j-1}-(1-\sigma)\left(D_{i-1, j}+D_{i+1, j}\right) \\
V_{i+1, j+1} & : D_{i+1, j}+D_{i, j+1}+A \\
V_{i+1, j-1} & : D_{i+1, j}+D_{i, j-1}-A \\
V_{i-1, j+1} & : D_{i-1, j}+D_{i, j+1}-A \\
V_{i-1, j-1} & : D_{i-1, j}+D_{i, j-1}+A \\
V_{i+2, j} & : D_{i+1, j} \\
V_{i-2, j} & : D_{i-1, j} \\
V_{i, j+2} & : D_{i, j+1} \\
V_{i, j-2} & : D_{i, j-1}
\end{aligned}\right.
$$

488 where $A=\frac{1-\sigma}{8}\left(D_{i+1, j+1}-D_{i-1, j+1}-D_{i+1, j-1}+D_{i-1, j-1}\right), \quad d x=d y=\lambda$, and all of the 489 coefficients must be divided by $\lambda^{4}$.

491 values need to be calculated. Linear algebraic equations that incorporate the coefficients in Eq.

492 (A2) can be used to calculate the deflection values as follows:

$493 \overrightarrow{R V}=-\left(\rho_{\mathrm{c}}-\rho_{\mathrm{f}}\right) \overrightarrow{g h}-\left(\rho_{\mathrm{m}}-\rho_{\mathrm{c}}\right) \vec{g} \vec{w}$,

494 where $\vec{V}$ is the deflection vector (a column vector with $\mathrm{M} \times \mathrm{N}$ rows), $\mathrm{R}$ is the difference 495 coefficient matrix (a matrix with $\mathrm{M} \times \mathrm{N}$ columns and $\mathrm{M} \times \mathrm{N}$ rows), and $\vec{h}$ and $\overrightarrow{\mathrm{w}}$ are the final 496 surface and subsurface topography vectors (column vectors with $\mathrm{M} \times \mathrm{N}$ rows), respectively. We 497 employed periodic boundary conditions during the calculations, and 24 kinds of boundary 498 conditions that should be considered (Eq. A2 and Fig. A1). Furthermore, compression of the 
499 sparse matrix R is recommended since it contains very few nonzero elements.

500

501

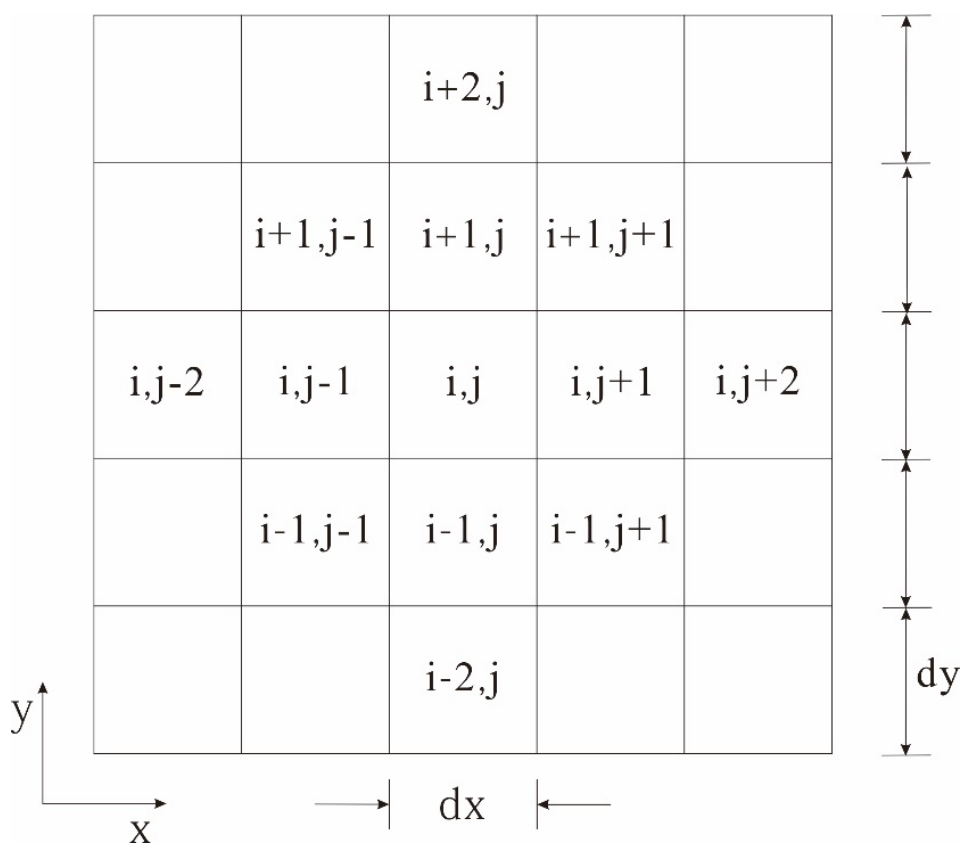

502 Fig. A1. Schematic diagram of the central difference grid.

(a)
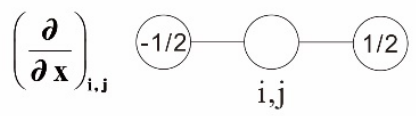

(b)
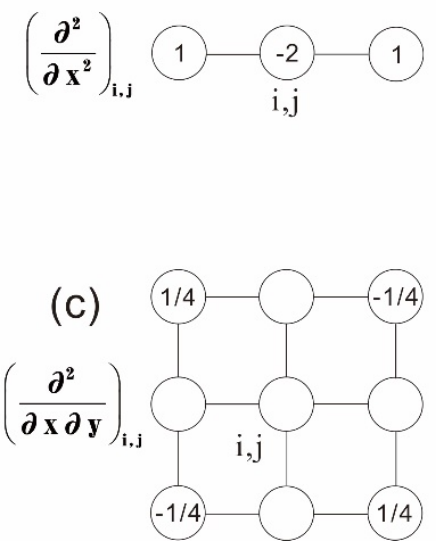

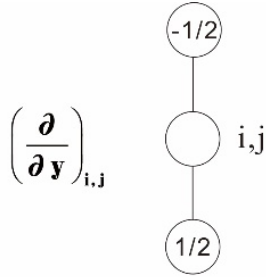

(1)

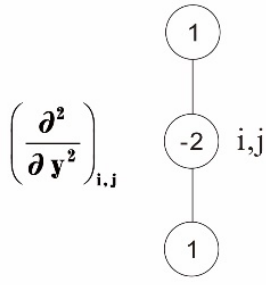

(d)

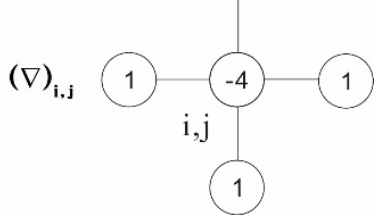


505 First-order differential operations. (b) Second-order differential operations. (c) Second-order

506 mixed partial differential operations. (d) Laplace differential operations. Null nodes indicate zero 507 coefficients. 


\section{Figures}

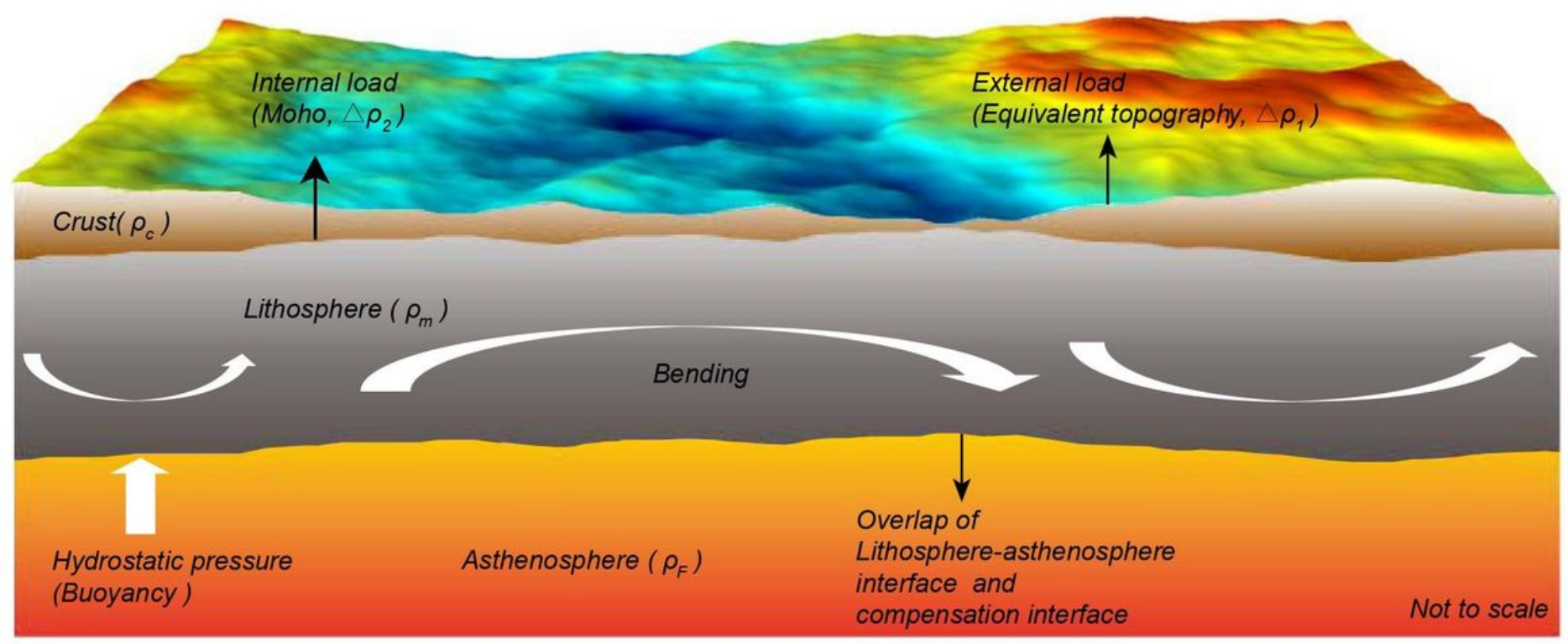

\section{Figure 1}

Conceptual mechanical model of the lithosphere and asthenosphere. 
Before flexure

a

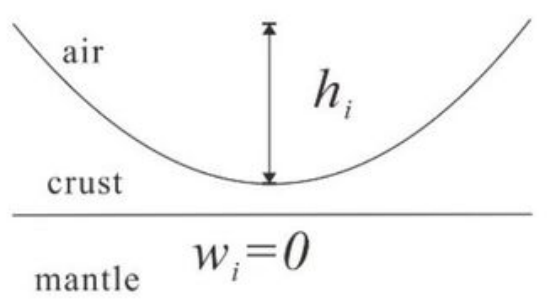

$$
h_{i}=0
$$

b

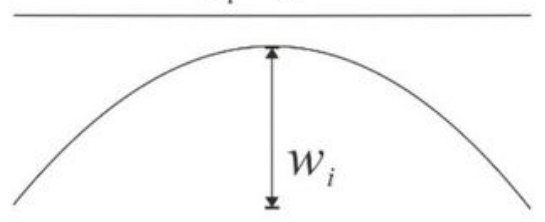

C

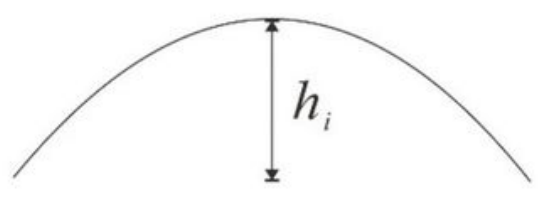

$$
w_{i}=0
$$

d

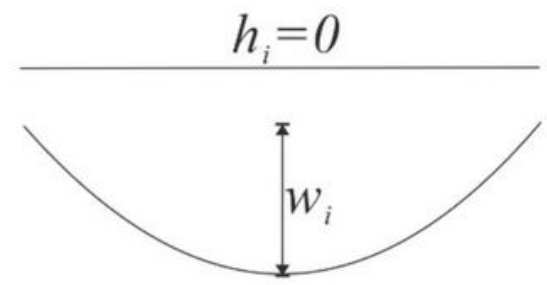

After flexure

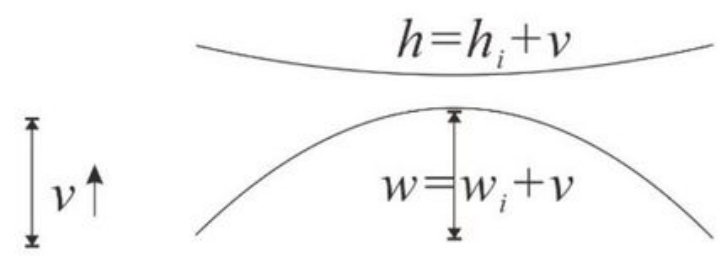

$\pm v \downarrow$
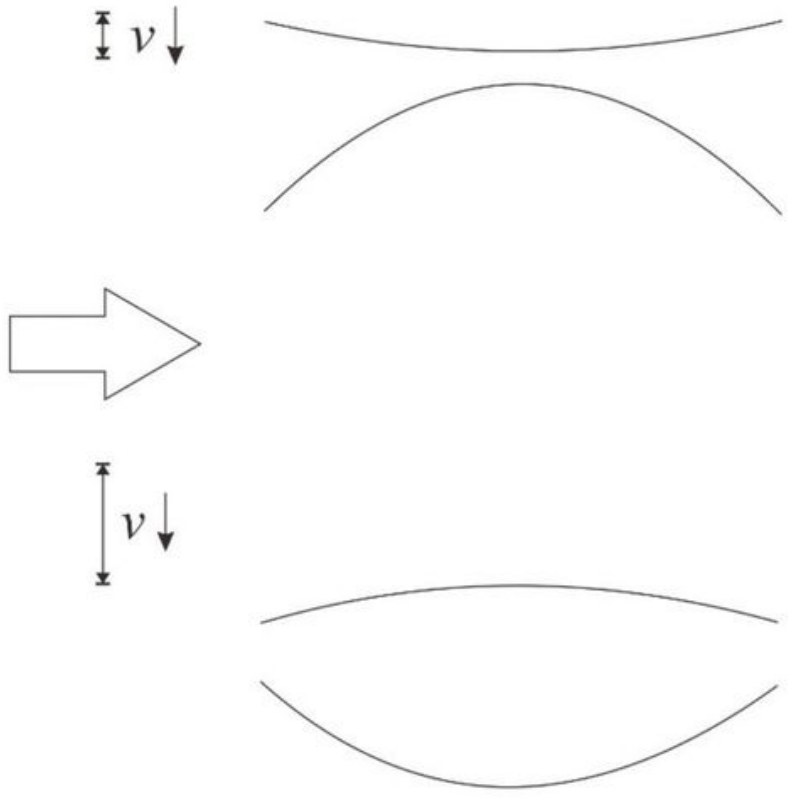

$\underline{\underline{1}} v \uparrow$

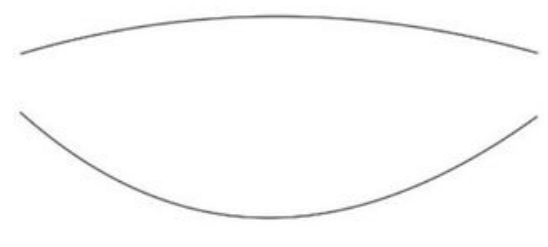

\section{Figure 2}

Schematic cross sections illustrating the response of an elastic plate to four end-member models. (a) Concave topography with an initial external (surface) load only. (b) Concave topography with an initial internal (subsurface) load only. (c) Convex topography with an initial external (surface) load only. (d) Convex topography with an initial internal (subsurface) load only. 

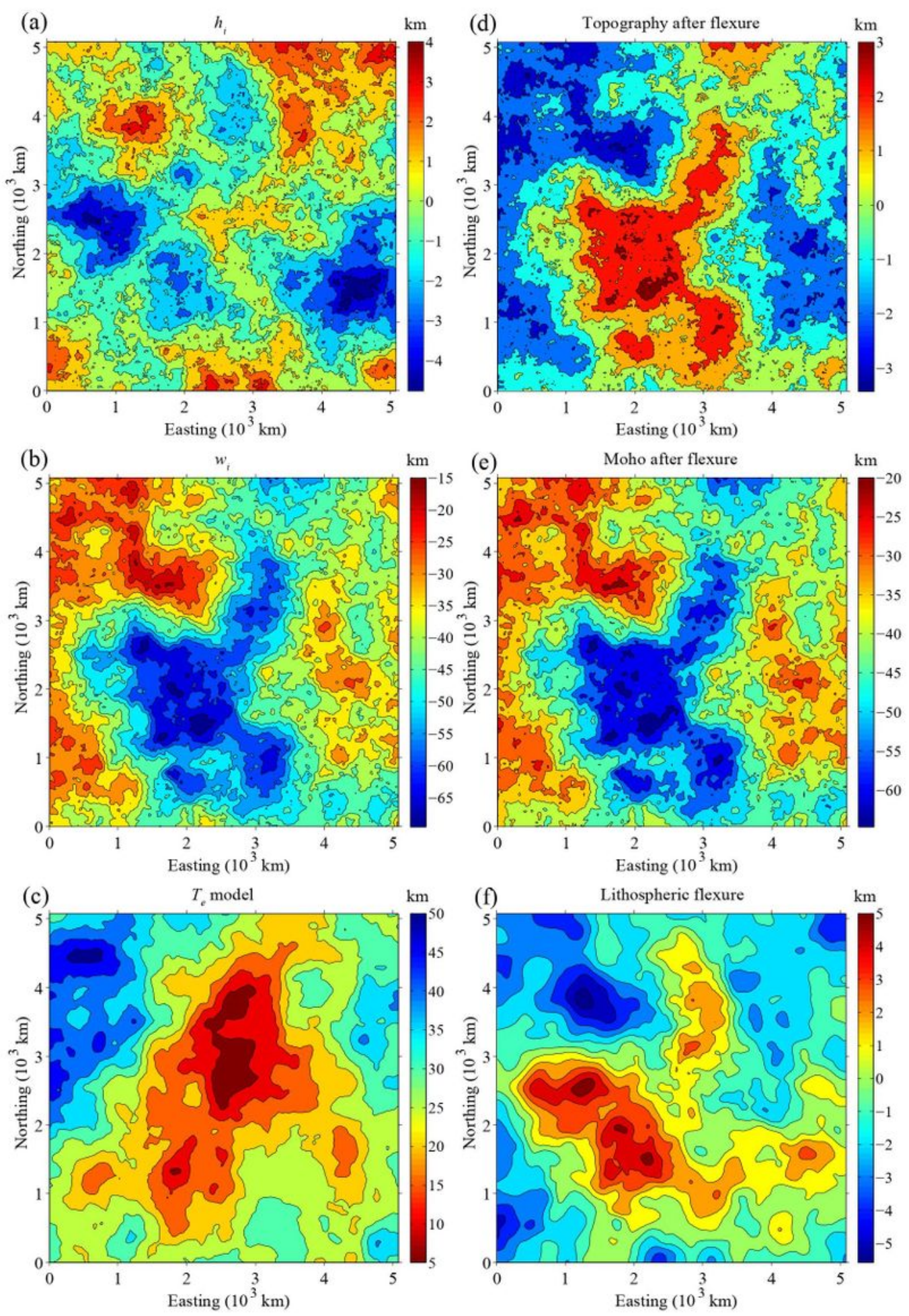

Figure 3

(a) initial surface (hi), (b) initial subsurface (wi), (c) model, (d) topography after flexure, (e) Moho after flexure, and (f) lithosphere flexure. 


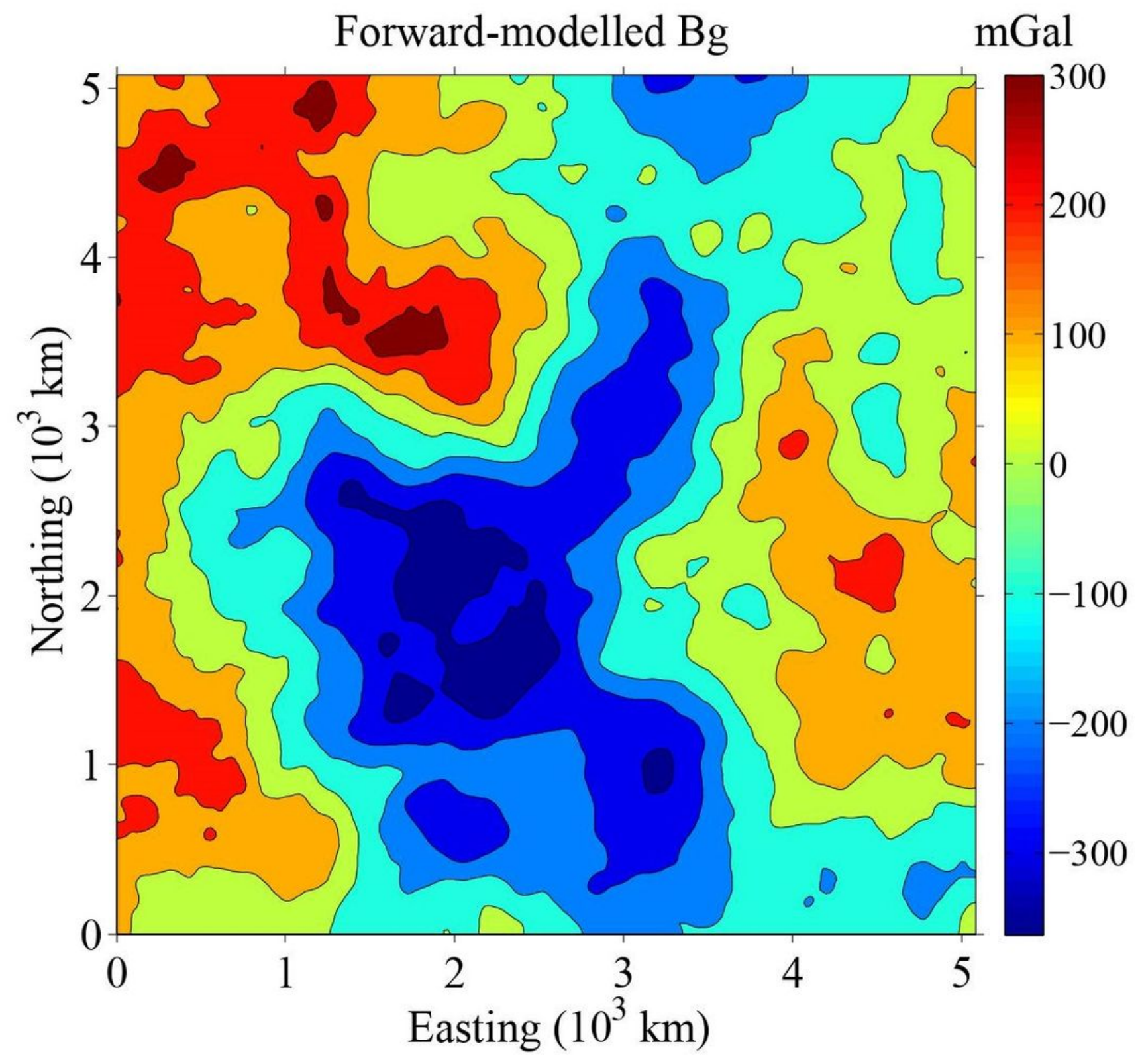

Figure 4

Forward-modelled Bouguer gravity anomaly (Bg). 

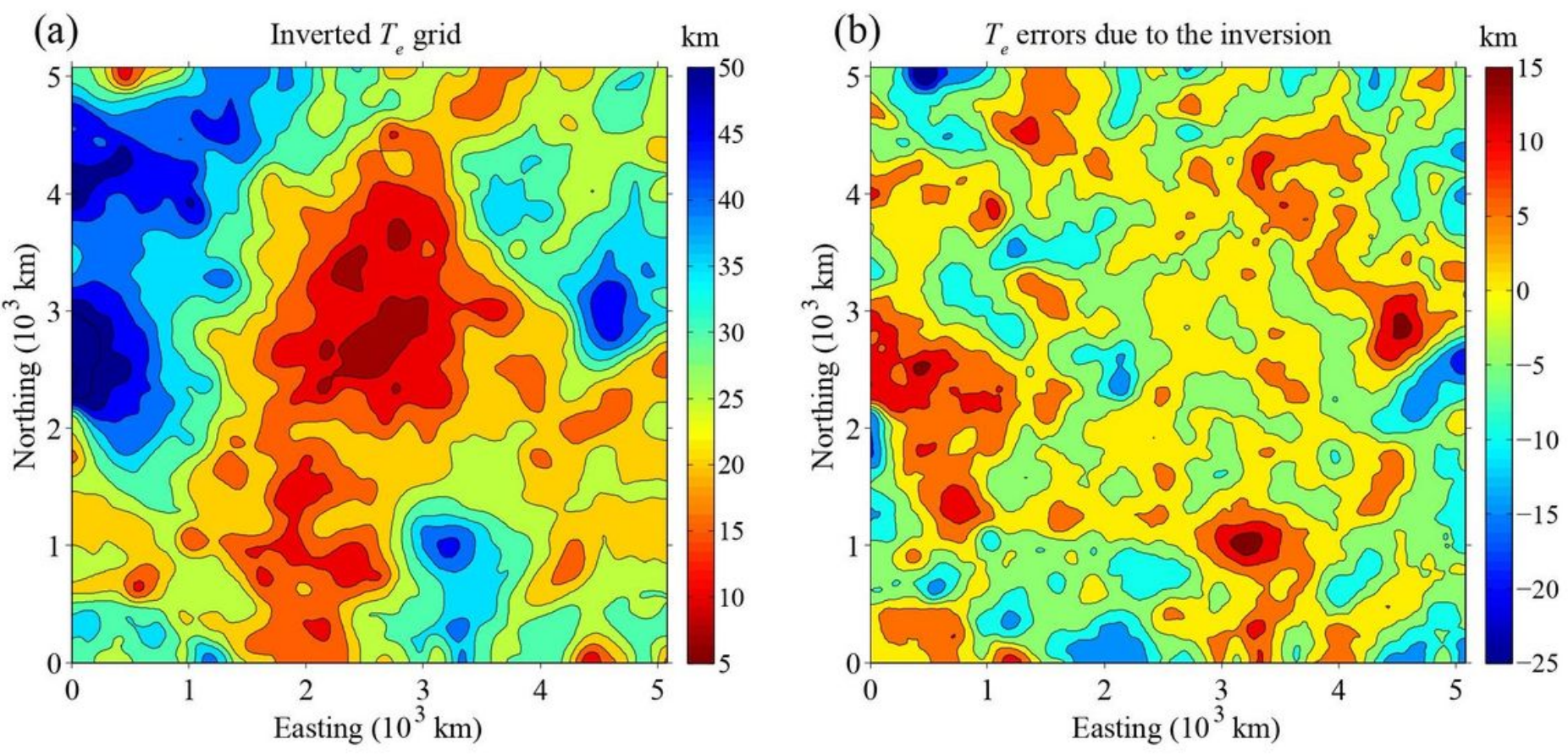

Figure 5

(a) Inverted Te grid. (b) Te errors due to the inversion.

(a) Lithospheric flexure with inverted $T_{e} \quad \mathrm{~km}$

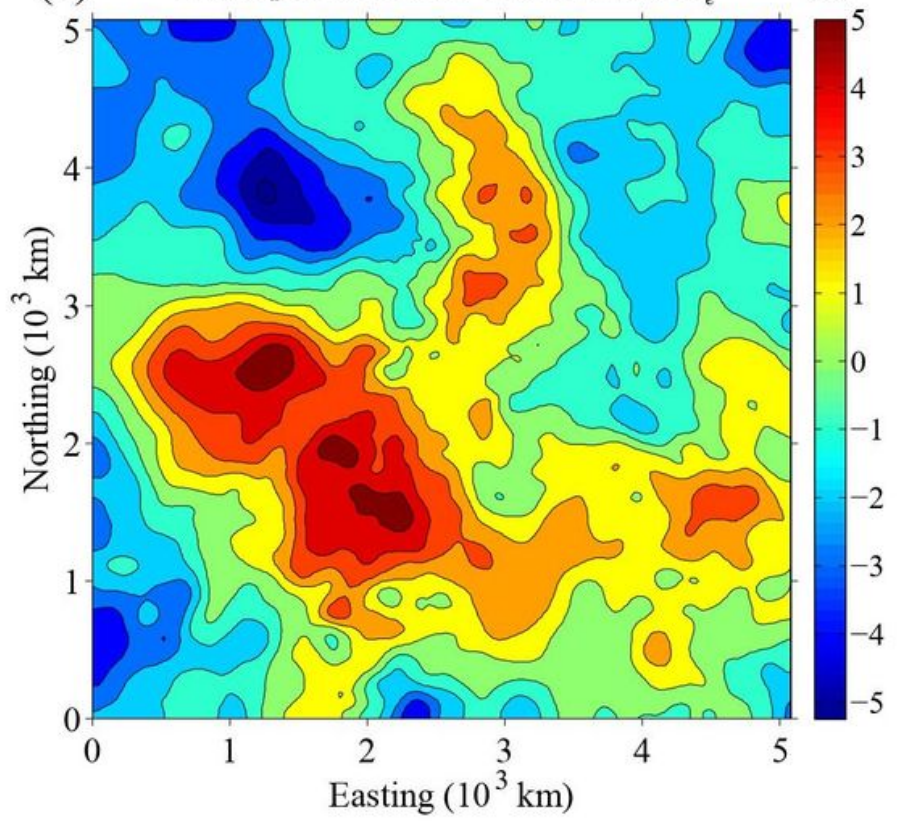

(b) Lithospheric flexure errors with inverted $T_{e} \quad \mathrm{~km}$

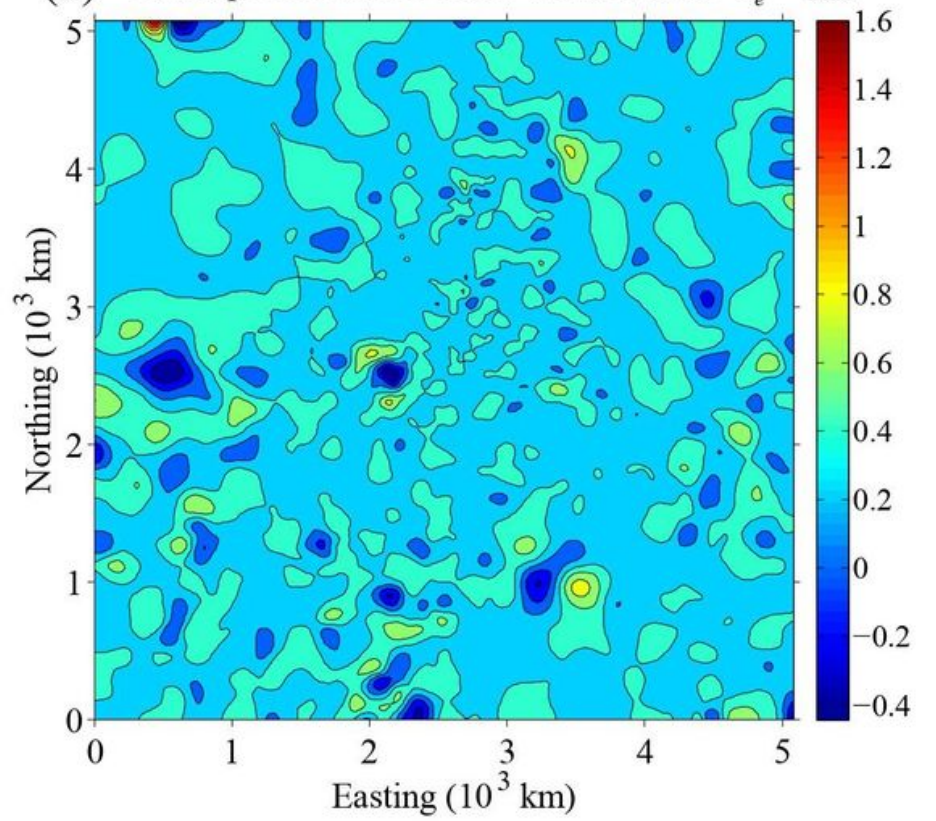

Figure 6

(a) Lithospheric flexure using the inverted Te grid. (b) Lithospheric flexure errors for the model inversion using the inverted Te grid. 

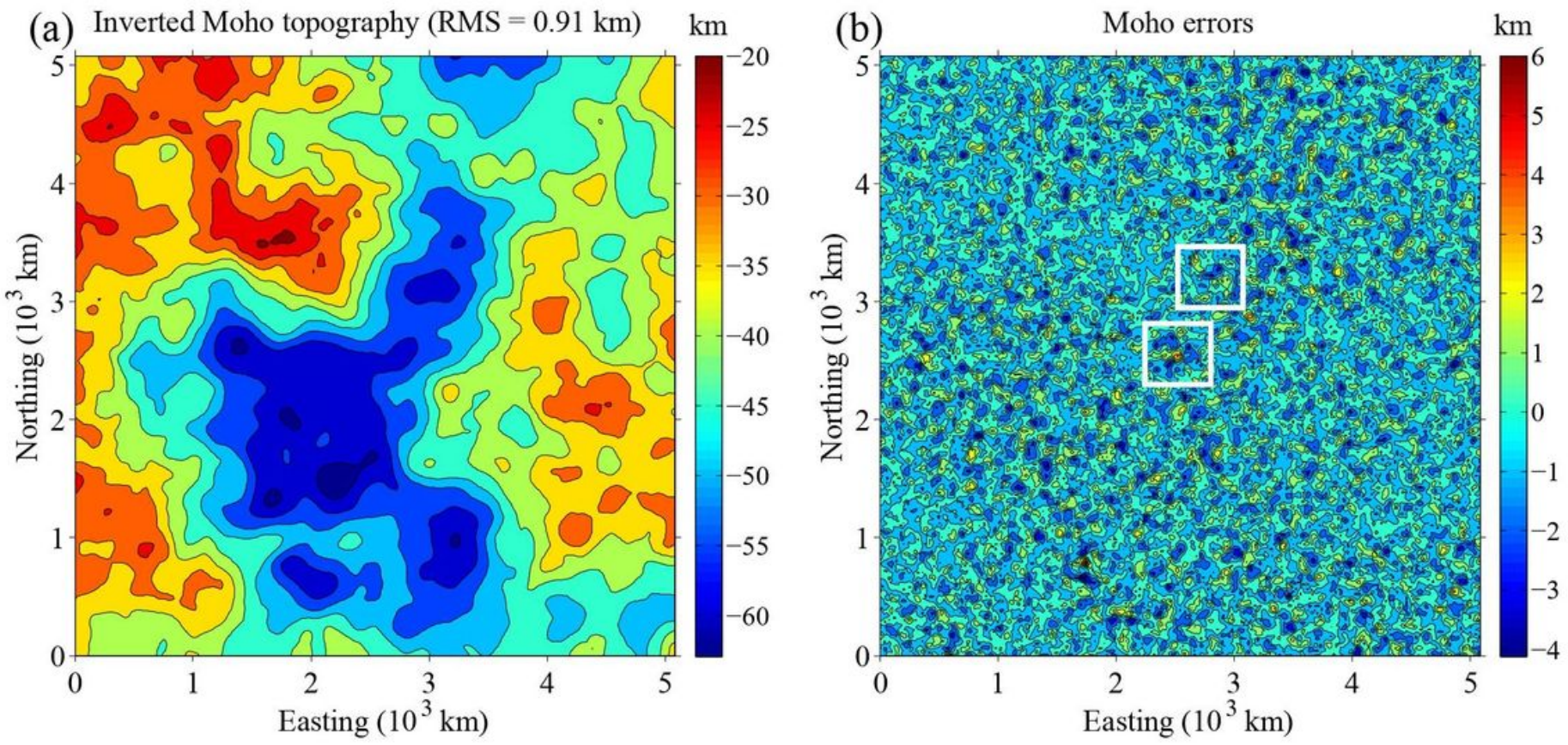

Figure 7

(a) Inverted Moho topography with the forward-modelled Bouguer anomaly (Bg). (b) Moho errors.

(a) Lithoshperic flexure with inverted Moho

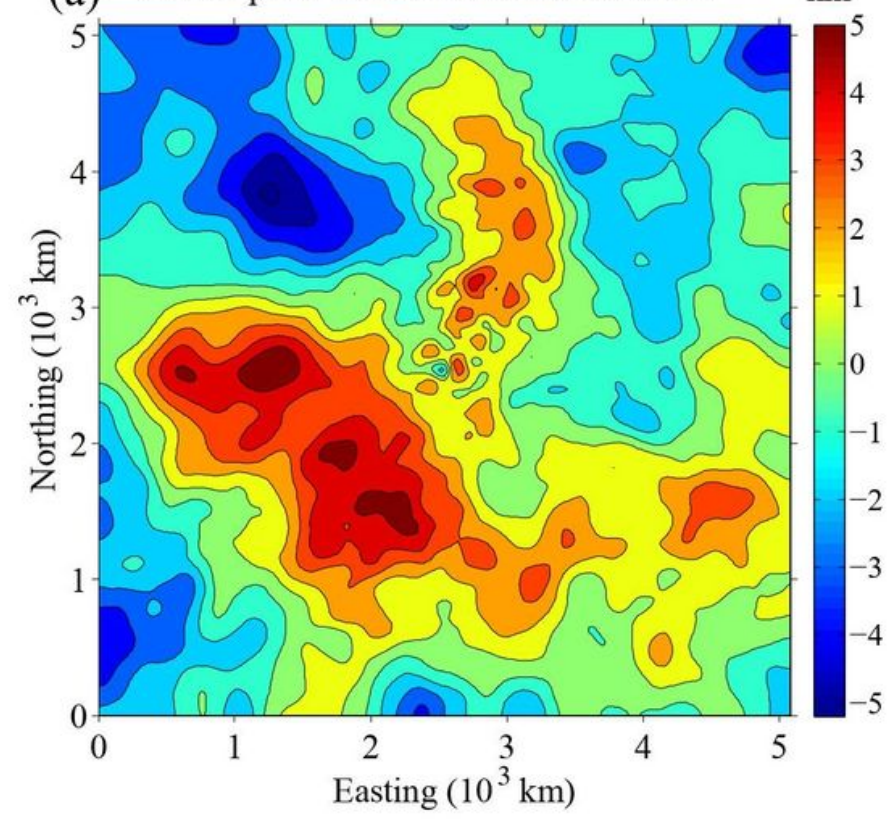

(b) Lithoshperic flexure errors with inverted Moho $\mathrm{km}$

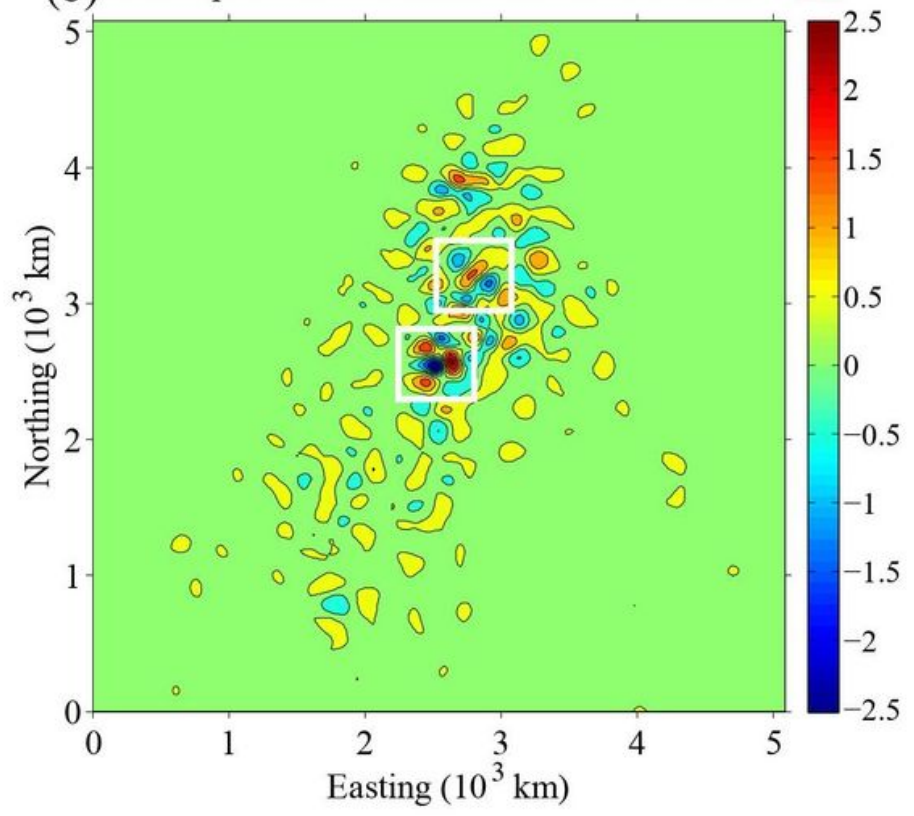

Figure 8

(a) Lithospheric flexure using the inverted Moho values. (b) Lithospheric flexure errors for the model inversion using the inverted Moho values 
(a) Lithospheric flexure with inverted Moho and $T_{e} \quad \mathrm{~km}$

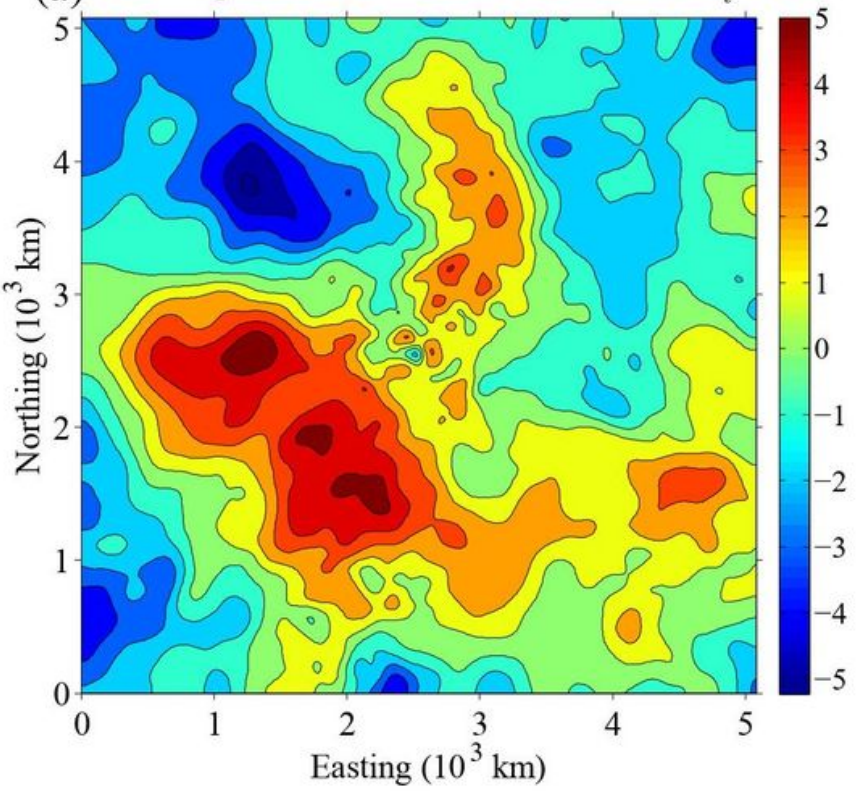

(b) Lithospheric flexure errors with inverted Moho and $T_{e} \quad \mathrm{~km}$

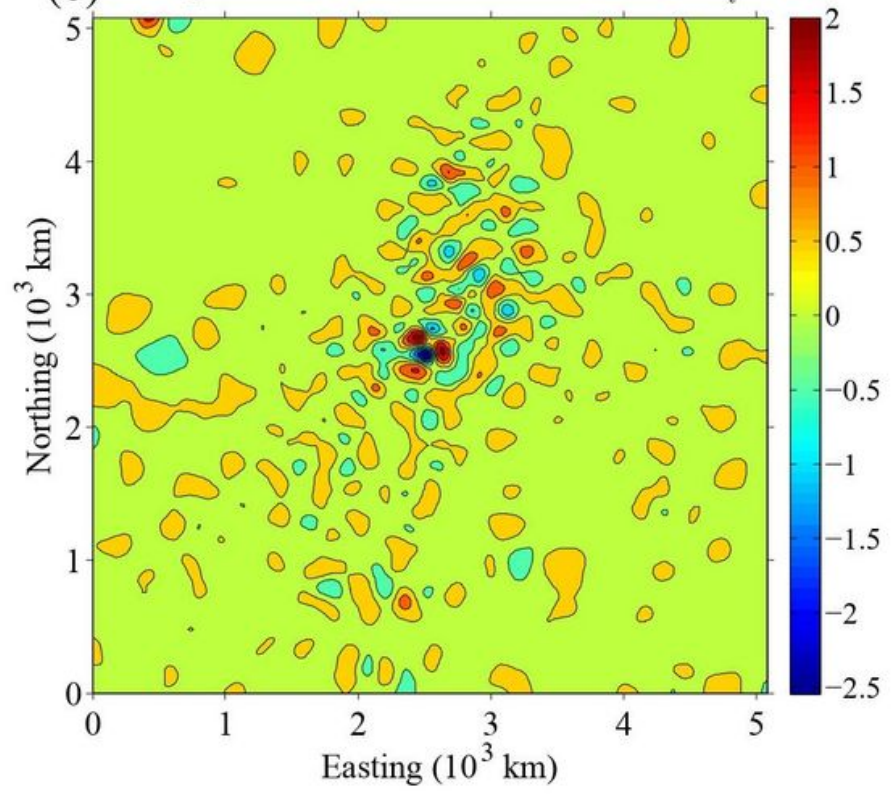

Figure 9

(a) Lithospheric flexure using the inverted Moho and Te values. (b) Lithospheric flexure errors from the model inversion using the inverted Moho and Te values.

\section{Supplementary Files}

This is a list of supplementary files associated with this preprint. Click to download.

- A1.png

- A2.png

- graphicalabstract01.jpg 